San Jose State University

SJSU ScholarWorks

Master's Theses

Master's Theses and Graduate Research

Spring 2016

\title{
Synthesis and Studies of Polymers Crosslinked with Electrochemically Degradable Crosslinking Reagents
}

Raymond Phillip Meury

San Jose State University

Follow this and additional works at: https://scholarworks.sjsu.edu/etd_theses

\section{Recommended Citation}

Meury, Raymond Phillip, "Synthesis and Studies of Polymers Crosslinked with Electrochemically

Degradable Crosslinking Reagents" (2016). Master's Theses. 4698.

DOI: https://doi.org/10.31979/etd.24dd-yk6g

https://scholarworks.sjsu.edu/etd_theses/4698

This Thesis is brought to you for free and open access by the Master's Theses and Graduate Research at SJSU ScholarWorks. It has been accepted for inclusion in Master's Theses by an authorized administrator of SJSU ScholarWorks. For more information, please contact scholarworks@sjsu.edu. 
SYNTHESIS AND STUDIES OF POLYMERS CROSSLINKED WITH ELECTROCHEMICALLY DEGRADABLE CROSSLINGING REAGENTS

\author{
A Thesis \\ Presented to \\ The Faculty and Department of Chemistry \\ San José State University \\ In Partial Fulfillment \\ of the Requirements for the Degree \\ Master of Science
}

By

Raymond Phillip Meury

May 2016 
(C) 2016

Raymond Phillip Meury

ALL RIGHTS RESERVED 
The Designated Thesis Committee Approves the Thesis Titled

SYNTHESIS AND STUDIES OF POLYMERS CROSSLINKED WITH ELECTROCHEMICALLY DEGRADABLE CROSSLINGING REAGENTS

by

Raymond Phillip Meury

APPROVED FOR THE DEPARTMENT OF CHEMISTRY

SAN JOSÉ STATE UNIVERSITY

May 2016
Dr. Marc d'Alarcao
Department of Chemistry
Dr. Rodger Terrill
Department of Chemistry
Dr. David Brook
Department of Chemistry 


\section{ABSTRACT \\ SYNTHESIS AND STUDIES OF POLYMERS CROSSLINKED WITH ELECTROCHEMICALLY DEGRADABLE CROSSLINGING REAGENTS}

\section{By Raymond Phillip Meury}

Crosslinked polymers have a covalent bridge that connects two polymer strands at multiple points, creating a network or matrix that is very robust. These types of polymers may either be stable indefinitely, or degrade over time; those that degrade over time typically do so at a constant rate. What is not available currently is a polymer that is stable indefinitely, but then can be degraded on command. Being able to create an adhesive that could undergo de-bonding on command would be very useful. We have designed an electrochemically degradable crosslinking reagent (EDCR) composed of a bi-functional polymer crosslinking moiety and an electroactive core that undergoes degradation under reductive conditions. The EDCR is composed of a quinone center with two terminal amines attached. This crosslinker will be used to make a reversible epoxy adhesive. Epoxys are two-component adhesives that consist of a crosslinking amine hardener and an epoxide-containing polymer resin. Mixing of these components leads to a reaction between the epoxy groups and the terminal amines on the hardener. This work shows the construction of a protected form of an EDCR. Once deprotected, it should work as a hardener that will be stable indefinitely, but will degrade with the application of a low voltage current. 


\section{ACKNOWLEDGEMENTS}

I would like to start by thanking my research advisor Marc d'Alarcao for being there for me throughout my time at SJSU. I have learned more from Prof. d'Alarcao than any other professor; I have learned to look at problems more critically and logically. I cannot thank him enough for all the ways he has helped me with my research, in addition to becoming a better chemist. He has also been there anytime I have needed advice outside of chemistry. Prof. d'Alarcao has been more than understanding and helpful when it came to raising my son while making my way through the master's program. I would also like to thank my committee members Prof. Roger Terrill and Prof. David Brook for taking time out of their schedule to be on my committee and help better my thesis work. I would like to thank Dr. Melody Esfandiari who has made me a better teacher and helped me significantly in my writing skills. I could not have made it though this master's program as easily without the help of my friends, fellow graduate students and TA's Tony Pan, John Kim, Jamie Lunkley, Victoria Chang, Thanh Ngoc-Le, and Tim Hom, without whom I would have been lost my first years teaching and my time would not have been as enjoyable at SJSU. I would like to thank my lab mates in the d'Alarcao lab who made the late nights entertaining. Lastly, I am most grateful for my son Jaxon Meury, who has been my biggest motivation for doing my best while at SJSU. And of course my parents for being extraordinarily supportive of me in so many ways while out here in California. 


\section{TABLE OF CONTENTS}

Page

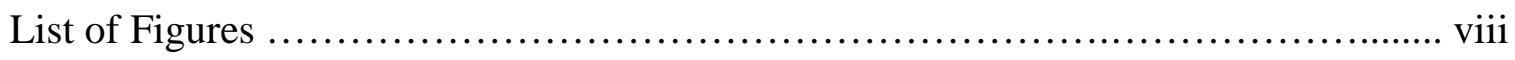

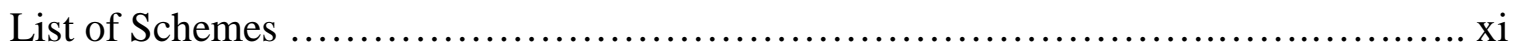

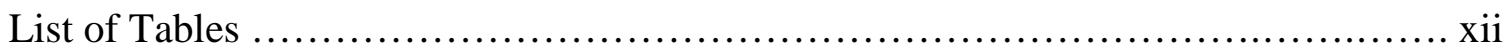

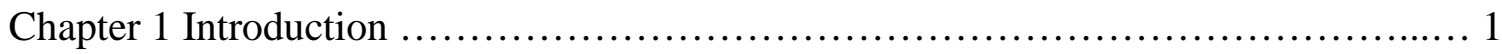

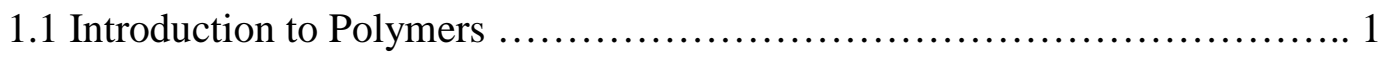

1.1.1 Crosslinked Polymers ................................. 2

1.1.2 Applications of Crosslinked Polymers ...................... 3

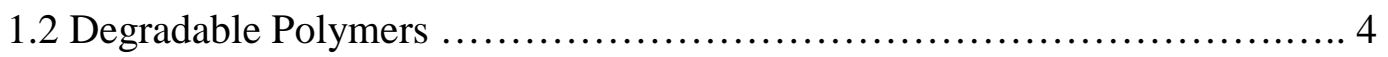

1.2.1 On Command Degradation .............................. 5

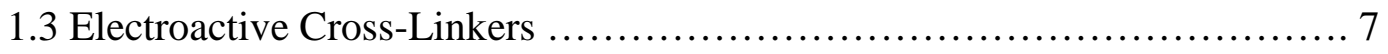

1.3.1 Trialkyl Lock Phenomenon ............................... 8

1.3.2 Amide Cleavage ...................................... 11

1.3.3 General EDCR Core Structure ........................... 12

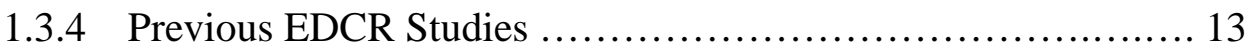

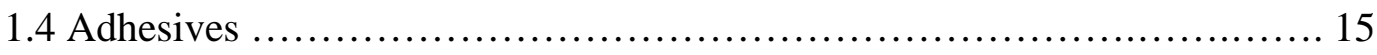

Chapter 2 Research Goals and Synthetic Plan ................................. 17

2.1 Research Goals ................................................. 17

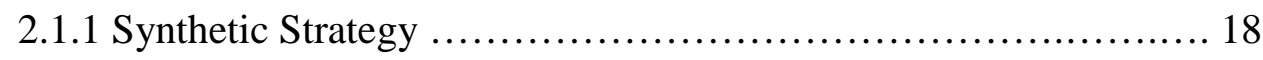

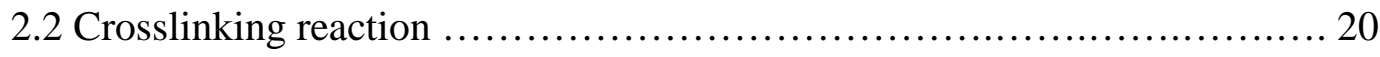

2.2.1 Electrochemical Degradation ............................ 21 


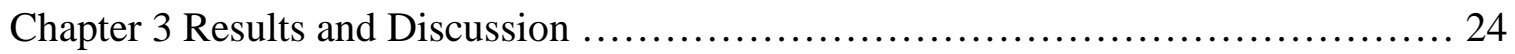

3.1 Diamine epoxide crosslinking EDCR .............................. 24

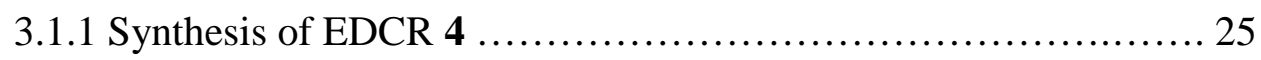

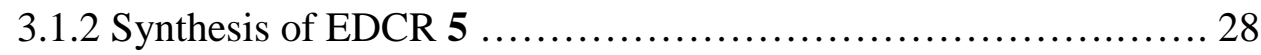

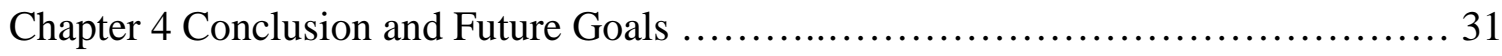

4.1 Conclusion .................................................... 31

4.1.1 Future Studies ............................................. 32

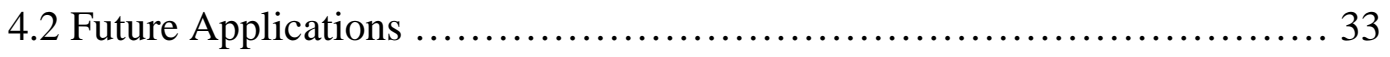

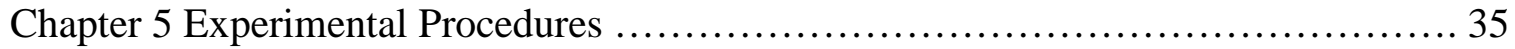

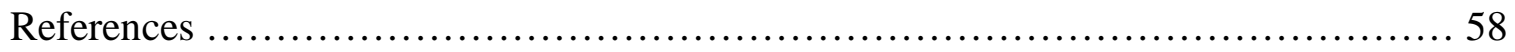




\section{LIST OF FIGURES}

Figure 1. Lactonization of o-hydroxyhydrocinnamic acid and methyl derivatives ....................................................... 9

Figure 2. Structure of the alcohol analog of pentamethyl-ohydroxyhydrocinnamic acid (A). Predicted conformation of pentamethyl-o-hydroxyhydrocinnamic acid (B). Conformation of the unmethylated hydroxyhydrocinnamic acid (C). Structure of pentamethylhydrocoumarin (D) .................................. 10

Figure 3. Reduction of amide quinone to corresponding lactone and amine ....... 11

Figure 4. Core structure of EDCR. X represents reactive functional group ........ 12

Figure 5. Reduction of EDCR crosslinked with polymer $\ldots \ldots \ldots \ldots \ldots \ldots \ldots \ldots \ldots$

Figure 6. Previously designed EDCRs (a) divinyl-sulfide, (b) divinylsulfone, and (c) divinyl-benzene ................................ 14

Figure 7. Studies on the electrolysis of divinyl-sulfide EDCR using MS ......... 15

Figure 8. Reaction of diamine hardener with epoxied containing polymer

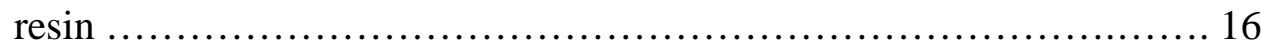

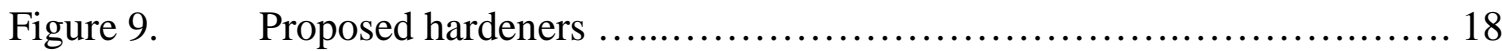

Figure 10. Crosslinking reaction of hardener $\mathbf{4}$ with a general polymer resin

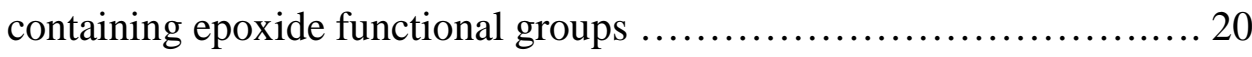

Figure 11. Reductive degradation of crosslinked polymer via hardener 4 to lactone $\mathbf{8}$ and corresponding amine attached to polymer

Figure 12. Intramolecular conjugate addiction reactions of hydroxypropyl- $p$ benzoquinone under acidic and alkali conditions 
Figure 13. Proposed product of hardener $\mathbf{4}$ after deprotection of the amines forming eight membered rings .................................... 28

Figure 14. 2,5-Dimethylquinone synthesis .................................. 34

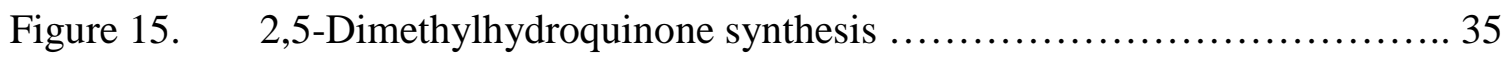

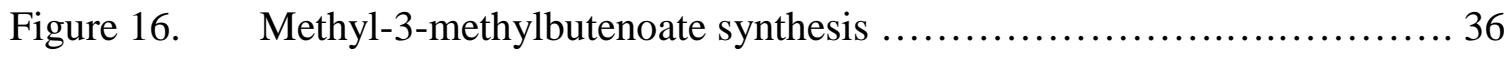

Figure 17. $\quad{ }^{1} \mathrm{H}$ NMR spectra of methyl-3-methylbutenoate in deuterated chloroform (7) ................................................... 37

Figure 18. 4,8-Dihydro-9,10-dimethyl-1,5-dioxa-3,3,7,7-tetramethyl-2,6anthraquinone synthesis ............................................ 38

Figure 19. $\quad{ }^{1} \mathrm{H}$ NMR spectra of 4,8-dihydro-9,10-dimethyl-1,5-dioxa3,3,7,7-tetramethyl-2,6-anthraquinone in deuterated chloroform (8)

Figure 20. 1,4-Bis(1,1-dimethyl-3-propanoic acid)-2,5-dimethylquinone synthesis ......................................................... 40

Figure 21. Mass Spectra of 1,4-Bis(1,1-dimethyl-3-propanoic acid)-2,5-

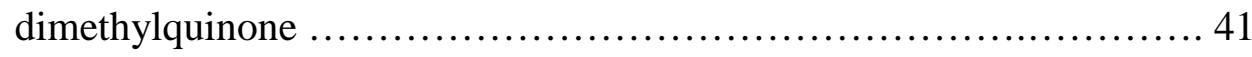

Figure 22. tert-Butyl (2-aminoethyl)carbamate synthesis ...................... 42

Figure 23. Mass spectra of tert-butyl (2-aminoethyl)carbamate .................... 43

Figure 24. Di-tert-butyl (((3,3'-(2,5-dimethyl-3,6-dioxocyclohexa1,4-diene-1,4-diyl)bis(3-methylbutanoyl))bis(azanediyl)) bis(ethane-2,1-diyl))dicarbamate synthesis .......................... 44

Figure 25. $\quad{ }^{1} \mathrm{H}$ NMR spectra of di-tert-butyl (((3,3'-(2,5-dimethyl-3, 6-dioxocyclohexa-1,4-diene-1,4-diyl)bis(3methylbutanoyl))bis(azanediyl))bis(ethane-2,1-diyl)) dicarbamate (11) 
Figure 26. Mass spectra of di-tert-butyl (((3,3'-(2,5-dimethyl-3,6

-dioxocyclohexa-1,4-diene-1,4-diyl)bis(3-

methylbutanoyl))bis(azanediyl))bis(ethane-2,1-diyl))

dicarbamate

Figure 27. 2,2'-((3,3'-(2,5-Dimethyl-3,6-dioxocyclohexa-1,4-diene-

1,4-diyl)bis(3-methylbutanoyl))bis(azanediyl))bis

(ethan-1-aminium) synthesis

Figure 28. Crude ${ }^{1} \mathrm{H}$ NMR spectra of

2,2'-((3,3'-(2,5-dimethyl-3,6-dioxocyclohexa-1,4-diene-1,

4-diyl)bis(3-methylbutanoyl))bis(azanediyl))bis(ethan-

1-aminium) in deuterium oxide (20)

Figure 29. 2,2'-(1,4-Phenylene)bis(ethan-1-amine) synthesis

Figure 30. $\quad{ }^{1} \mathrm{H}$ NMR spectra of 2,2'-(1,4-phenylene)bis(ethan-1-amine)

in deuterated methanol (13)

Figure 31. tert-Butyl (4-(2-aminoethyl)phenethyl)carbamate synthesis

Figure 32. $\quad{ }^{1} \mathrm{H}$ NMR spectrum of tert-butyl (4-(2-aminoethyl)phenethyl) carbamate in deuterated chloroform (14) 52

Figure 33. 3,3'-(2,5-Dimethyl-3,6-dioxocyclohexa-1,4-diene-1,4-diyl)

bis(N-(4-(2-aminoethyl)phenethyl)-3-methylbutanamide)

synthesis 53

Figure 34. $\quad{ }^{1} \mathrm{H}$ NMR spectrum of 3,3'-(2,5-dimethyl-3,6-dioxocyclohexa1,4-diene-1,4-diyl)bis(N-(4-(2-aminoethyl)phenethyl)-3-

methylbutanamide) in deuterated chloroform (15) 54

Figure 35. Mass spectra of 3,3'-(2,5-dimethyl-3,6-dioxocyclohexa-1,4-diene-1,4diyl)bis(N-(4-(2-aminoethyl)phenethyl)-3-methylbutanamide) 55 


\section{LIST OF SCHEMES}

Scheme 1. Retro-synthetic scheme for hardeners $\mathbf{4}$ and $\mathbf{5}$

Scheme 2. Acylation reaction of 2,5-dimethylhydroquinone 6 with

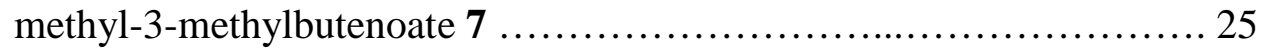

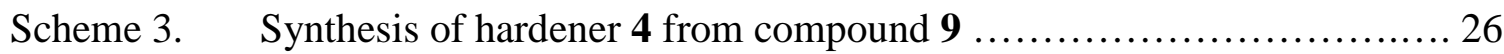

Scheme 4. Synthesis of Boc protected amine arm for formation of compound 5

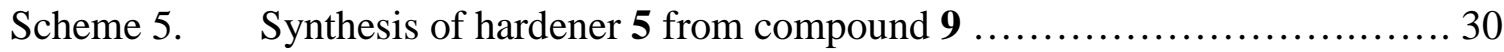




\section{LIST OF TABLES}

Table 1. Specific rate constants for lactonization $\left(\mathrm{M}^{-1} \mathrm{sec}^{-1}\right)$.

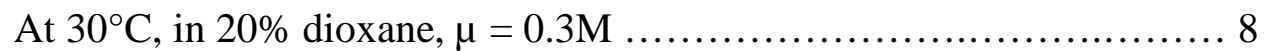




\section{CHAPTER 1}

\section{INTRODUCTION}

\subsection{INTRODUCTION TO POLYMERS}

Polymers are large molecules composed of repeating, covalently bound monomer units. Polymers are typically of high molecular weights, melting and boiling points, and are synthesized both in nature and in the lab. Polymers are studied in many fields such as biology, polymer chemistry, macromolecular science, and physics. They are found naturally as macromolecules such as proteins, nucleic acids, and oligosaccharides. They are also made synthetically from natural monomers, for example rubber from isoprene and styrofoam from styrene. ${ }^{1}$ The covalently bound chains of monomer units usually contain carbon, hydrogen, and oxygen atoms, but can also contain sulfur, fluorine, silicon, and phosphorous atoms. The monomer units combine to form polymers by a process called polymerization, which covalently links repeating monomers into a chain to form larger macromolecules. ${ }^{2}$

Depending on the initial monomer unit, different types of polymers can be made.

There are three general categories of polymers: linear, branched, and crosslinked. Linear polymers are the simplest kinds of polymers, with monomer units connected in one continuous length. ${ }^{3}$ Linear polymers can pack closely together to form crystalline structures, but since they are able to move past one another quite easily, they can also be very flexible. Some examples of linear polymers are polyethylene and polystyrene. The backbone of polyethylene is composed of a continuous chain of $\mathrm{CH}_{2}$ groups. Branched polymers are polymers with more than one point of monomer connectivity. Branching of 
the polymer makes it difficult for the polymer to pack in a regular array, like linear polymers; therefore they are less crystal-like and less dense. ${ }^{4,5}$ An example of a branched polymer is a dendritic polymer, where the amount of branching affects the melting and boiling points of the polymer. Crosslinked polymers contain short chains that connect different polymer strands in a matrix or network. ${ }^{6}$ An example of a crosslinked polymer is a hydrogel, which is made up of crosslinked hydrophilic polymer strands that can absorb large amounts of water. ${ }^{7}$ Polymers are typically very durable and some have thermally and electrically insulating properties. They can be lightweight yet mechanically robust.

\subsubsection{CROSSLINKED POLYMERS}

Crosslinked polymers have properties that differ depending on the amount of crosslinking. The extent of crosslinking determines the elasticity of the polymer; the more crosslinks there are, the stiffer or more ridged the polymer becomes. Crosslinked polymers are found both in nature and in human-made form. Some proteins are naturally occurring crosslinked polymers. The crosslinking in these proteins is important for generating mechanically stable structures such as hair, skin, and cartilage. They are mostly crosslinked via disulfide bridges but also by isopeptide bonds. Natural rubber is a linear polymer of isoprene units, but is synthetically made stronger by a process called vulcanization. Vulcanization is the process in which crosslinks are introduced to increase the melting point and rigidity of rubber. Car tires and early bowling balls are made of vulcanized rubber. ${ }^{8}$ Vulcanization is the chemical process of adding sulfur or other equivalent curatives at high temperatures to a polymer, thus making it more durable; this 
is why vulcanization is named after the Roman god of fire. Charles Goodyear first used this process in the 1840 s after he noticed that adding sulfur to natural rubber and heating it increased the strength of the material. This helped to increase its strength and prevented the rubber from losing its shape at high temperatures, which is ideal for car tires. ${ }^{9,10}$ The success of Charles Goodyear's vulcanization process significantly expanded the field of polymer chemistry. The first semi-synthesized polymer was nitrocellulose, produced by esterifying cellulose with nitric acid, invented by Christian Schonbein. ${ }^{10}$

\subsubsection{APPLICATIONS OF CROSSLINKED POLYMERS}

Polymers are used in many different fields due to their strength and overall durability. For example, polyacrylamide gels, synthetically crosslinked polymers, are used for gel electrophoresis, which is a method for separating and analyzing macromolecules. Supramolecular hydrogels are widely used in agriculture, ${ }^{17}$ tissue engineering, ${ }^{17}$ and biomedical devices in the body. Degradable and non-degradable polymers are utilized in the biomedical field today. ${ }^{11}$

Crosslinked polymers are also valuable in drug delivery applications. Most nondegradable polymers used in drug delivery are reservoir-type systems, which consist of a drug core surrounded by a permeable non-degradable polymer membrane that allows the drug to diffuse into the body. For example, Norplant ${ }^{\circledR}$ is a birth control system with silicon-rubber encapsulated levonorgestrol that is implanted inside the upper arm subdermally, which allows for near steady diffusion of levonorgestrol for 5 years or until removed. ${ }^{12}$ While the duration of delivery is very convenient, a surgical procedure is 
required for the implantation and removal. In addition, long-term implantation can lead to toxic dumping of the drug.

In some applications, the drug can be covalently attached to the polymer for slow hydrolytic release, 5-fluorouracil can be covalently bound to polyamidoamine dendrimers, and methotrexate can be bound to hydrazide-terminated dendrimers. ${ }^{13}$ However, these polymers tend to prematurely expel drugs prior to reaching their target destination. $^{14}$

Degradable polymers, on the other hand, do not need to be surgically removed; instead, they are absorbed or excreted by the body. For instance, degradable sutures are a copolymer of polyacetic acid/polyglycolic acid. They are hydrolyzable and they slowly degrade over time after applied to a wound. ${ }^{15}$ Hydrolytic or enzymatic degradation of drug-containing hydrogels is also used today. ${ }^{16}$ Polyesters have gained a lot of attention since they are hydrolyzed readily and produce non-toxic byproducts such as polypeptides and polysaccharides. ${ }^{20}$

\subsection{DEGRADABLE POLYMERS}

Polymer degradation results in a change in tensile strength, color or molecule weight. Degradation is accomplished via heat, light or chemical means. ${ }^{17}$ Degradation of polymers leads to the breakdown of the macromolecule into smaller molecules or into their monomer units. For crosslinked polymers, it is usually the severing of the crosslinkage between two polymer strands. Polymer degradation is not always a desirable process. Cracking of rubber hoses in car engines is clearly unwanted. Another example of undesired degradation is proteolytic hydrolysis of supramolecular hydrogels, 
which can lead to premature chemical degradation. ${ }^{18}$ Supramolecular hydrogels are "host" polymers that can crosslink copolymers bearing "guest" molecules such as biomolecules. Other times degradation can be quite desirable, for instance in the degradable sutures mentioned in the previous section.

Another example would be hydrogels, since they are capable of absorbing biomolecules and large amounts of water, and can be degraded near infrared light. ${ }^{19}$ This can be used for drug delivery where the degradation of the hydrogel would release the biomolecules at a localized site in the body; however, chemical degradation can lead to premature dumping in the body. ${ }^{20}$ Branched molecules such as dendrimers can also act as drug delivery molecules since they are able to trap small molecules, like Bengal Rose dye. These small molecules cannot diffuse out of the dendrimer "box", and are only released upon enzymatic or photochemical degradation of the polymer. ${ }^{21,22}$ Polymers are typically stable indefinitely, or designed to degrade over time. Those that degrade over time typically do so at a constant rate. ${ }^{23}$ What would be advantageous is a polymer that is stable indefinitely, but then can be degraded on command.

\subsubsection{ON-COMMAND DEGRADATION}

On-command degradation could be very useful in the adhesives industry. Being able to create an adhesive that could undergo de-bonding on command would be very useful in a variety of industrial settings. The first step in creating a polymer that could undergo degradation on command would be to determine the best method for degradation. As stated earlier, degradation of polymers is accomplished using heat, light, or chemical means. 
Heat would not be the most preferred method, especially when used for adhesives in industrial settings. Either excess heat would be required to induce de-bonding, in which case the heat could damage the material being adhered, or if it only took a small amount of heat to achieve de-bonding, then that would severely limit the available applications since sunlight or mechanically produced heat would initiate the degradation process. Light would also not be the most desirable means of degradation, since adhesives are used in such a wide variety of applications that limiting a de-bonding adhesive to materials that do not encounter sunlight would not be practical. In addition, adhesives typically bond two surfaces together, making it hard for the light to reach much of the adhesive. Chemical means of de-bonding seems to be the best choice, but it would come with a plethora of problems such as having a possible environmental impact, high costs, and negative chemical side reactions with the materials being adhered. Therefore, a novel method of polymer degradation would have to be devised.

Electrolysis has to potential to be a suitable degradation method for devising a reversible adhesive. Using electrolysis as a method for degradation would avoid all the disadvantages that come with the methods used today. Electrolysis is cheap, since it only requires the administration of a low voltage current, there are no environment impacts, there are few applications where there would be a negative effect on the material being adhered, and unless the object being adhered is hit by lightning there is little chance of any unwanted degradation, which would be the least of your worries in that case.

Organic polymers can be manipulated to have unique redox properties that allow electrons to be transferred along the crosslinker. Some common conducting polymers in 
use today are polypyrrole, poly(3,4-ethylenedioxythiophene) (PEDOT), poly-Nmethylpyrrole, and polyaniline (PANI). ${ }^{24}$ These are currently used in biomedical applications such as nerve regeneration and drug delivery. For example, polypyrrole being electrically conductive is used to enhance nerve cell interaction and nerve growth. ${ }^{25}$ Polypyrrole is also used as a delivery device for the drugs adenosine 5-triphosphate, ${ }^{26}$ heparin, ${ }^{27}$ and glutamate. ${ }^{24}$ The conductivity of these polymers is due to the conjugated $\pi$-bonds.

Degradation of crosslinked polymers is typically achieved by severing the crosslinker. Since the amount of crosslinks determines the rigidity of the polymer, severing the crosslinker would reduce the tensile strength, melting and boiling points, and overall durability of the polymer. Therefore, to develop an on-demand degradable crosslinked polymer, the target site for degradation would be the crosslinks.

\subsection{ELECTROACTIVE CROSSLINKERS}

The first steps in developing an on-demand degradable crosslinked polymer would be to construct an electroactive crosslinker. One way to do this would be to make use of quinones, which are electroactive. Under reducing conditions, quinones are converted to hydroquinones, which have different reactivities. Therefore, one approach to creating an electrochemical degradable crosslinking reagent (EDCR) would be to use a quinone moiety as the core of the crosslinker.

\subsubsection{TRIALKYL LOCK PHENOMENON}

The trialkyl lock phenomenon can be used to couple the quinone reduction to the hydroquinone with the scission of a polymer crosslink. According to work done by 
Thorpe and Ingold, there is an increased rate of cyclization of methyl-substituted phenolic acid derivatives compared to unsubstituted analogs (Figure 1). It was observed that lactones formed faster despite angle strain when $\mathrm{R}_{1}-\mathrm{R}_{5}=\mathrm{CH}_{3}$ instead of $\mathrm{H}$. The rate of cyclization when $\mathrm{R}_{1}-\mathrm{R}_{5}=\mathrm{CH}_{3}$ is $3.4 \times 10^{11}$ times faster than when $\mathrm{R}_{1}-\mathrm{R}_{5}=\mathrm{H}$, as depicted in Table $1 .^{28}$

Table 1. Specific rate constants for lactonization $\left(\mathrm{M}^{-1} \sec ^{-1}\right)$. At $30^{\circ} \mathrm{C}$, in $20 \%$ dioxane, $\mu=0.3 \mathrm{M}^{30}$

\begin{tabular}{|c|c|c|}
\hline Alkyl Substitution & $\mathrm{K}^{9}$ & Relative Rate \\
\hline i. $\mathrm{R}_{1}-\mathrm{R}_{5}: \mathrm{H}$ & $5.9 \times 10^{-6}$ & 1.0 \\
\hline ii. $\mathrm{R}_{1}-\mathrm{R}_{3}: \mathrm{CH}_{3}$ & $4.0 \times 10^{-5}$ & 6.7 \\
\hline iii. $\mathrm{R}_{4}-\mathrm{R}_{5}: \mathrm{CH}_{3}$ & $2.6 \times 10^{-2}$ & $4.4 \times 10^{3}$ \\
\hline iv. $\mathrm{R}_{1}-\mathrm{R}_{5}: \mathrm{CH}_{3}$ & $2.0 \times 10^{6}$ & $3.4 \times 10^{11}$ \\
\hline
\end{tabular}<smiles>[R2]c1cc([R])c(C([R5])([R5])CC(=O)O)c(O)c1[R]</smiles>

i-v<smiles>[R]c1cc([R])c2c(c1[R])OC(=O)CC2([R6])[R5]</smiles>

$\mathrm{V}$

Figure 1. Lactonization of o-hydroxyhydrocinnamic acid and methyl derivatives. ${ }^{29}$

The gem-dialkyl group on C7 (Figure 1) interlocking with the C4 methyl group on the aromatic ring of phenolic acids produces a severe conformational restraint on the side chain. The crowding of the methyl groups places a steric burden on the already bulky molecule when not cyclized, placing the carboxylic acid group in proximity to the hydroxyl group, therefore cyclization becomes increasingly favorable. 
This observation is supported by X-ray crystal structure analysis of the lactone pentamethylhydrocoumarin and the alcohol analog of pentamethyl-ohydroxyhydrocinnamic acid. Figure 2 shows that the conformation of the alcohol $\mathbf{A}$ is similar to that of the lactone $\mathbf{D}$. The bond angles of the methylated acid $\mathbf{B}$ and lactone $\mathbf{D}$ were determined to be about $124^{\circ}$ for $\mathrm{C} 12-\mathrm{C} 4-\mathrm{C} 5$ and $127^{\circ}$ for $\mathrm{C} 4-\mathrm{C} 5-\mathrm{C} 7$. Additionally, the distances between atoms $\mathrm{O} 1$ and $\mathrm{C} 8$ in the lactone were found to be $2.42 \AA$, comparable to $2.8 \AA$ in the methylated acid $\mathbf{B}$, however the O1-C9 distance in the unmethylated acid $\mathbf{C}$ was found to be $4.3 \AA^{30}$

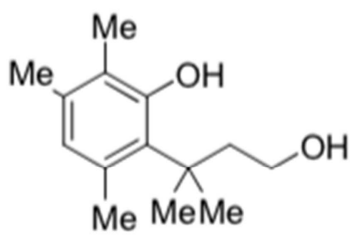

A

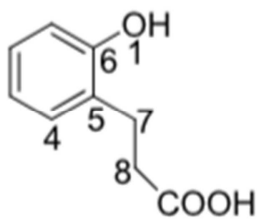

C

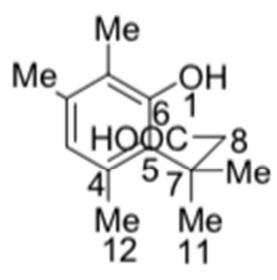

B

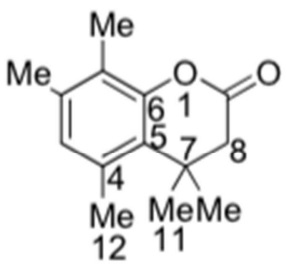

D

Figure 2. Structure of the alcohol analog of pentamethyl-ohydroxyhydrocinnamic acid (A). Predicted conformation of pentamethylo-hydroxyhydrocinnamic acid (B). Conformation of the unmethylated hydroxyhydrocinnamic acid (C). Structure of pentamethylhydrocoumarin (D).

Crystal structure analysis indicates that the steric hindrance of the gem-dialkyl groups on $\mathbf{C} 7$ with the methyl group on the ring force the acid portion of molecule $\mathbf{B}$ in 
close proximity compared to the unsubstituted analog so that it closely resembles that of the lactone $\mathbf{D}$. This close proximity is what causes the $3.4 \times 10^{11}$ fold increase in cyclization rate relative to the unsubstituted analog $\mathbf{C}$, which still thermodynamically favors cyclization.

\subsubsection{AMIDE CLEAVAGE}

The carboxylic acid on C8 of molecule $\mathbf{B}$ in Figure 2 will readily react with the hydroxyl group on the ring to form lactone $\mathbf{D}$. This reaction will not occur when the hydroxyl group is replaced by a carbonyl. It has been shown that amides and esters of methyl-substituted quinone acids also lactonize readily with the release of the corresponding amine under mild reducing conditions. ${ }^{31}$ When a methyl-substituted quinone amide is treated with sodium dithionate $\left(\mathrm{Na}_{2} \mathrm{~S}_{2} \mathrm{O}_{4}\right)$ an unstable intermediate hydroquinone is first formed, quickly followed by the corresponding lactone and amine (Figure 3). ${ }^{32}$ This observation was confirmed by monitoring the reaction using nuclear magnetic resonance (NMR) spectroscopy. It was observed that, as the reaction commenced, the peaks indicating the amide decreased and new peaks representing the subsequent lactone and amine increased. When the reaction reached completion there was an equimolar mixture of lactone and amine. ${ }^{33}$

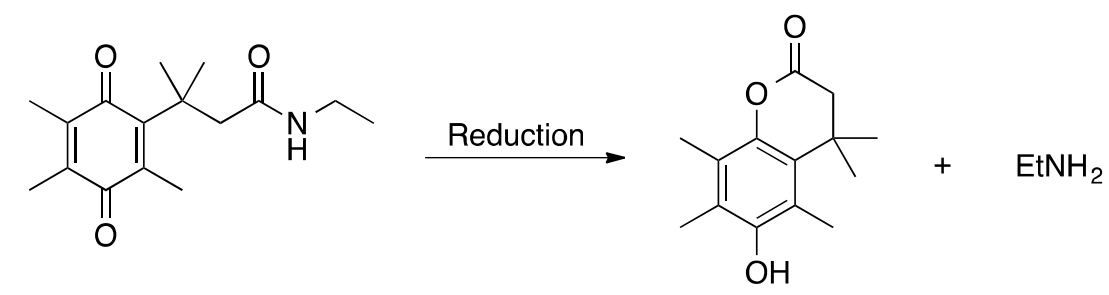

Figure 3. Reduction of amide quinone to corresponding lactone and amine. 


\subsubsection{GENERAL EDCR CORE STRUCTURE}

This research is what led the d'Alarcao group to the construction of their reducible crosslinker core (Figure 4). A quinone moiety with alkyl arms, an amide linkage and bifunctional, appendable crosslinking groups $\mathrm{X}$ was developed. The gemdialkyl and methyl groups on the ring are present to make use of the trialkyl lock phenomenon. Reactive function groups X could be engineered based on the polymer that is to be crosslinked. The reduction of the quinone to the unstable hydroquinone should cause the core to lactonize, uncrosslinking the polymer strands and leaving the reactive functional groups/amines on the polymer, making this an irreversible reaction. Destroying the crosslinks between the polymer strands drastically changes the physical properties of the polymer making it less rigid, reducing its tensile strength, and lowering its melting and boiling points.

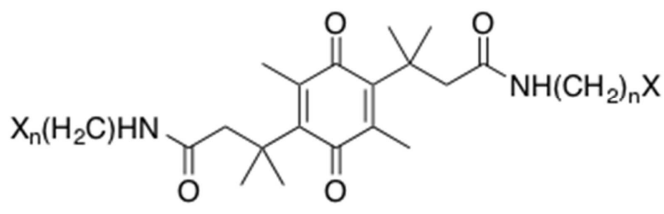

Figure 4. Core structure of EDCR. X represents reactive functional group.

The amide groups on this EDCR are in close proximity to the quinone carbonyl groups, similar to what is shown in Figure 2, due to the methyl substitutions. This allows for quick lactonization once the quinone is reduced to the unstable hydroquinone, breaking the amide bonds and uncrosslinking the polymers strands, as illustrated in Figure 5. 


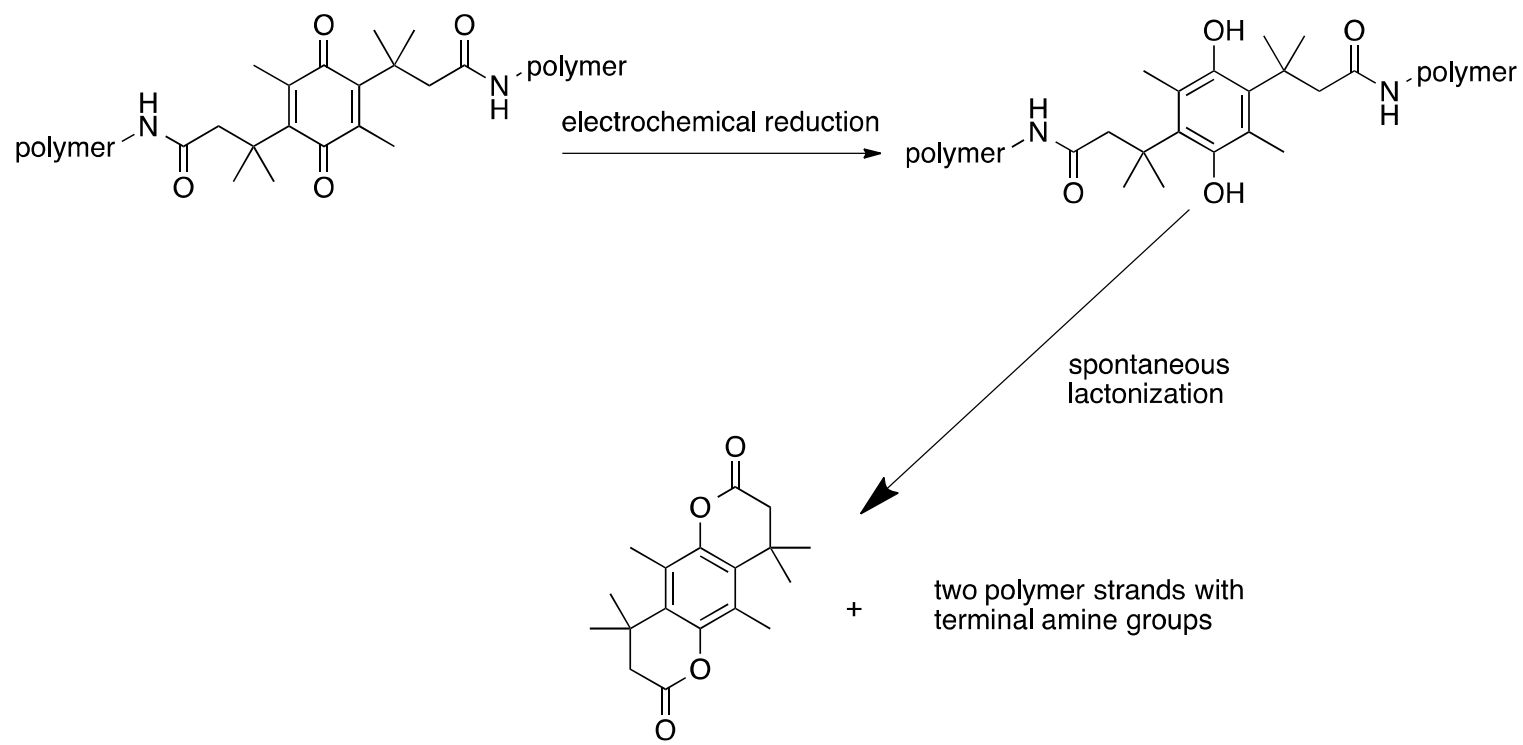

Figure 5. Reduction of EDCR crosslinked with polymer.

\subsubsection{PREVIOUS EDCR STUDIES}

Past work done by the d'Alarcao group includes synthesis of divinyl-sulfide, divinyl-sulfone, and divinyl-benzene EDCRs. Attempts to crosslink divinyl-sulfide EDCR with polyacrylamide were unsuccessful thus far, probably due to differences in the chemical structure of the crosslinker and the polymer. However, successful crosslinking of carboxymethylcellulose-hydroxyethylcellulose copolymer with divinyl-sulfone EDCR was achieved. Successful crosslinking of polystyrene beads with divinyl benzene EDCR was also achieved. ${ }^{34}$ Figure 6 shows the three EDCRs previously synthesized by the d'Alarcao group. ${ }^{35}$ 


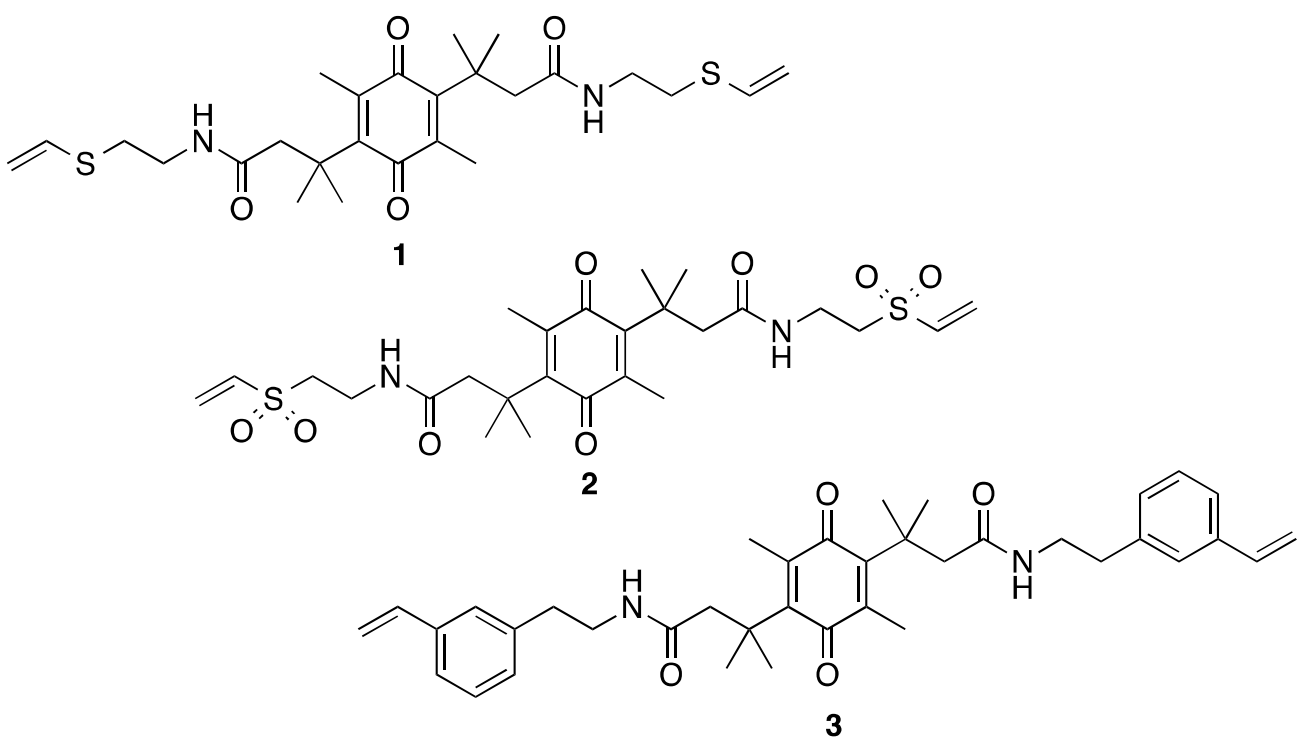

Figure 6. Previously designed EDCRs (1) divinyl-sulfide, (2) divinylsulfone, and (3) divinyl-benzene.

A kinetics experiment of divinyl-sulfide EDCR degradation was carried out. $\mathrm{H}^{1}$ NMR and mass spectrometry (MS) determined the disintegration of divinyl-sulfide EDCR into the lactone and amine from the amide linkages upon quinone reduction. In the graph shown in Figure 7 the divinyl-sulfide was electrochemically reduced and analyzed periodically using MS. ${ }^{34}$ The route of degradation of the amide was found to be through reduction of the quinone core to the hydroquinone, followed by the lactone and amine. The graph in Figure 7 shows that as the reaction proceeds, the amount of EDCR decreases; as this occurs there is an immediate increase in the amine, lactone, and hydroquinone. As is to be expected, the amount of hydroquinone initially increases, but since it is only an unstable intermediate, it subsequently diminishes to zero. In addition, as the reaction comes to an end, the amount of amine produced is almost twice that of the 
lactone as expected. The rate constant was determined to be $0.0014 \mathrm{~min}^{-1}$ for the degradation of the amide and was found to have a half-life of $495 \mathrm{~min}$.

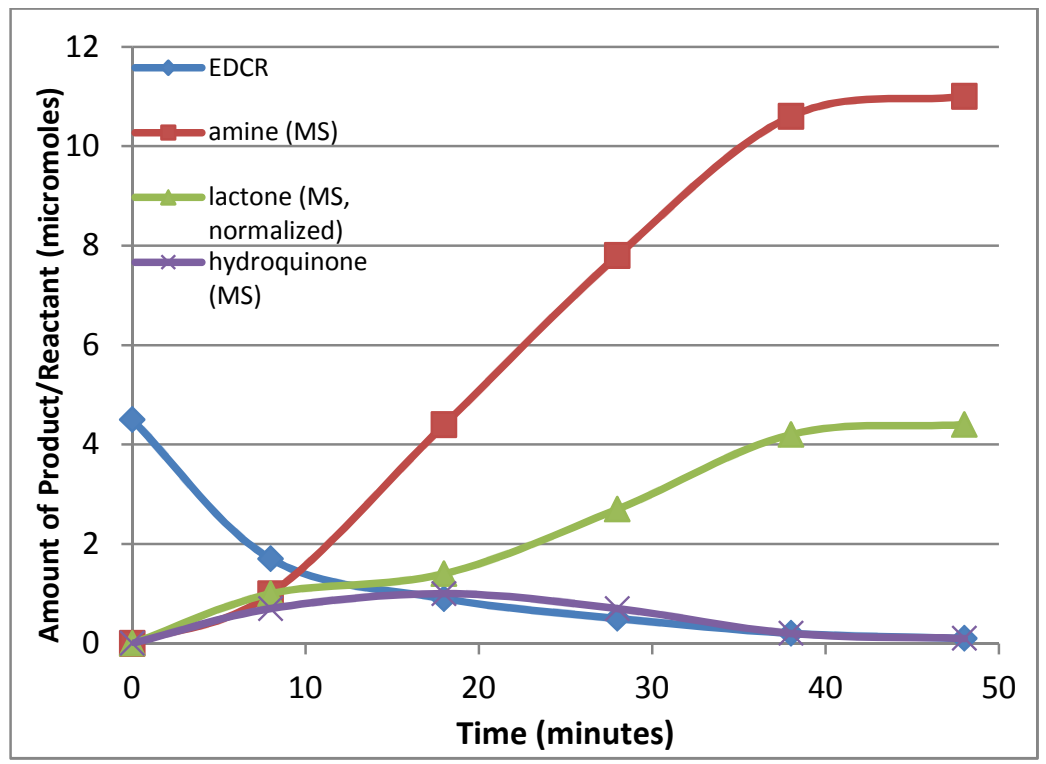

Figure 7. Studies on the electrolysis of divinyl-sulfide EDCR using MS..$^{34}$

\subsection{ADHESIVES}

A common adhesive used in industrial settings is epoxy. Epoxy adhesives can bond many different types of material such as wood, metal, glass, plastics, and stone. Furthermore, they are used in applications that require a high strength bond such as automobiles, aircrafts, bicycles, snowboards, etc. Epoxies are a very strong crosslinked polymer adhesives made by reacting two compounds, a resin polymer and a crosslinking hardener. These are contained separately until applied to the target surface where they cure and harden. The polymer resin is composed of monomer units that contain terminal epoxide functional groups. The hardener is a small crosslinking molecule with two terminal amine groups. Figure 8 shows how amines react with epoxides to form a covalent bond. The terminal amines on the hardener react with the epoxide groups on the 
polymer resin crosslinking the polymer strands to one another at multiple sites. This matrix of interconnected polymer strands solidifies, adhering any material it is in contact with.

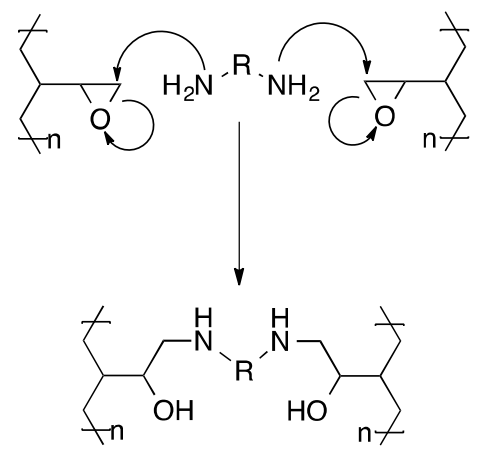

Figure 8. Reaction of diamine hardener with epoxy containing polymer resin. 


\section{CHAPTER 2}

\section{RESEARCH GOALS AND SYNTHETIC PLAN}

\subsection{RESEARCH GOALS}

Hereafter, this work will describe the development and synthesis of two EDCRs with terminal amine functional groups that will have the ability to crosslink a commercially available polymer resin with epoxide functional groups. The results of these novel hardeners to crosslink an epoxy resin and subsequently de-bonding under reducing conditions will be studied and characterized. The goal of this work is to develop a strong epoxy adhesive that can undergo electrochemical degradation on command, resulting in de-bonding. This research builds upon previous studies done by the d'Alarcao group in synthesizing the general core structure of the EDCR, and contains novel syntheses to develop functional groups capable of crosslinking a commercially obtained epoxy resin. Terminal diamine crosslinkers that make use of the trialkyl lock phenomenon to undergo on-command degradation are envisioned, as shown in Figure 9.<smiles>CC1=C(C(C)(C)CC(=O)NCCN)C(=O)C(C(C)(C)CC(=O)NCCN)=C(C)C1=O</smiles>

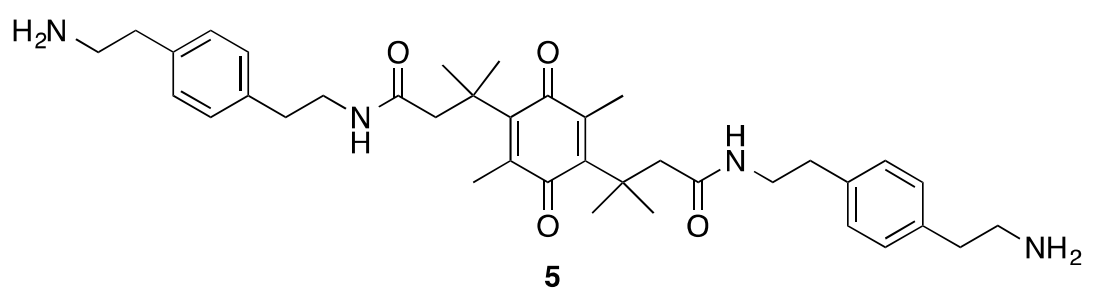

Figure 9. Proposed hardeners 


\subsubsection{SYNTHETIC STRATEGY}

A retro-synthetic scheme is shown in Scheme 1. Hardeners $\mathbf{4}$ and $\mathbf{5}$ are synthesized from a known compound previously made by the d'Alarcao group, di-acid 9, ${ }^{36}$ which can be coupled with a mono-Boc protected diamine. Mono-Boc protected diamine $\mathbf{1 0}$ is used to make hardener 4. Ethylenediamine (19) is selectively mono-Boc protected to make compound 10. In a similar fashion, hardener $\mathbf{5}$ is synthesized from the coupling of di-acid 9 with the mono-Boc protected diamine 14. 1,4

Phenylenediacetonitrile is reduced using Raney nickel to produce 2,2' -(1,4phenylene)bis(ethan-1-amine), which can subsequently be mono-Boc protected in a similar fashion as diamine $\mathbf{1 9}$. 
Scheme 1: Retro-synthetic scheme for hardeners 4 and $\mathbf{5}$.<smiles>CC1=C(C(C)(C)CC(=O)NCCN)C(=O)C(C(C)(C)CC(=O)NCCN)=C(C)C1=O</smiles><smiles>CC1=C(C(C)(C)CC(=O)NCCc2ccc(CCN)cc2)C(=O)C(C)=C(C(C)(C)CC(=O)NCCc2ccc(CCN)cc2)C1=O</smiles><smiles>C=CC=C1C(=O)C(C)=C(C(C)(C)CC(=O)O)C(C(C)(C)CC(=O)O)=C(C)C1=O</smiles>

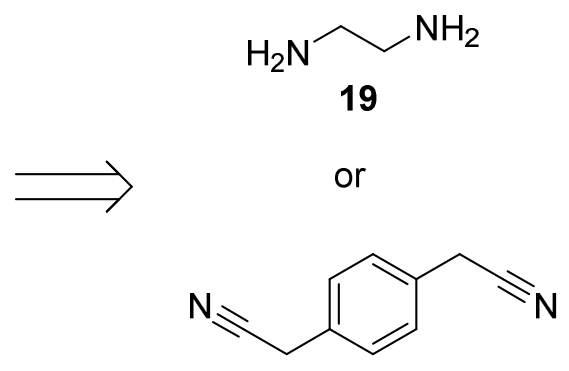




\subsection{CROSSLINKING REACTION}

Once hardeners $\mathbf{4}$ and $\mathbf{5}$ have been synthesized, the terminal amines should be able to react with epoxide groups on commercially available polymer resins. As the two terminal amines react with the epoxide groups forming covalent bonds, they would link together two separate polymer strands. Each hardener molecule would make this crosslinkage, creating a matrix of interconnected strands of polymers affixing into a solid amalgamation. This is how these hardeners will work as an adhesive. Figure 10 depicts how hardener $\mathbf{4}$ will crosslink two polymer resins with epoxide functional groups, hardener 5 would react analogously.

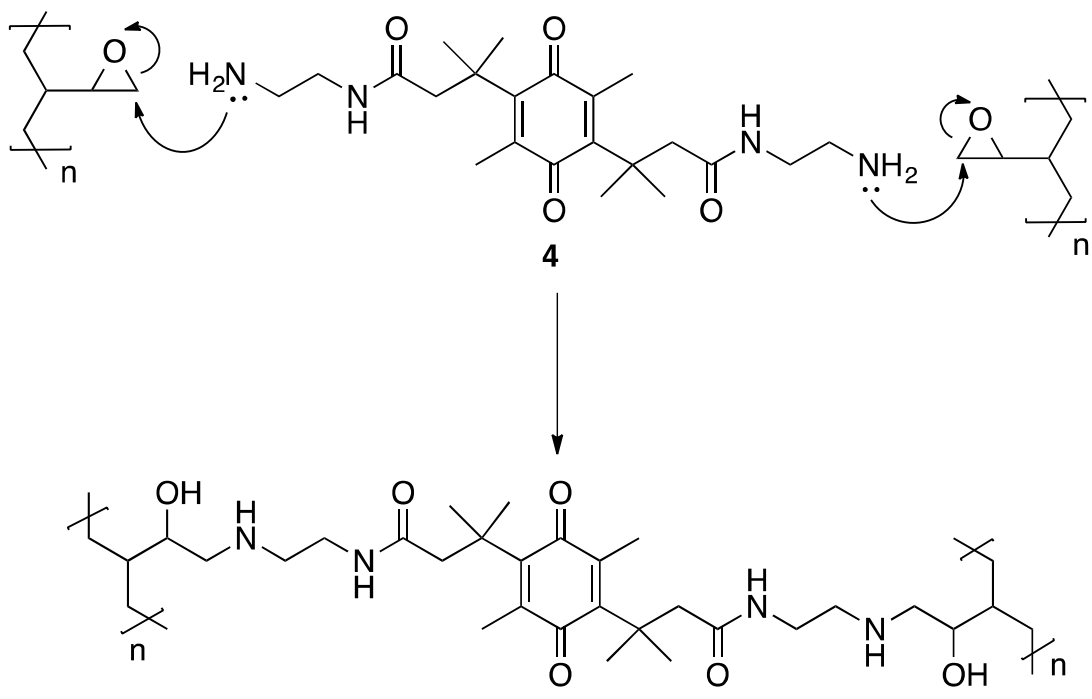

Figure 10. Crosslinking reaction of hardener $\mathbf{4}$ with a general polymer resin containing epoxide functional groups. 
The lone pair of electrons on the terminal amines react with an epoxide group on the polymer resin, opening the epoxide ring, forming a covalent bond between the resin and the hardener. This forms a crosslink between two resin polymer strands, which is sustained indefinitely. This leads to the curing/hardening of the material.

\subsubsection{ELECTROCHEMICAL DEGRADATION}

The crosslinked complex depicted in Figure 10 is stable until an outside action is applied. In the case of the hardeners presented in this paper, to de-bond the polymer resins via degradation, the application of an electrochemical reduction is required. Once the quinone of the hardener is reduced to the unstable intermediate hydroquinone, the amide bonds break and cyclize, forming the lactone $\mathbf{8}$. Since the amines are left attached to the polymer resins, this is an irreversible process. This process is shown in Figure 11 starting with the crosslinked complex from Figure 10. 

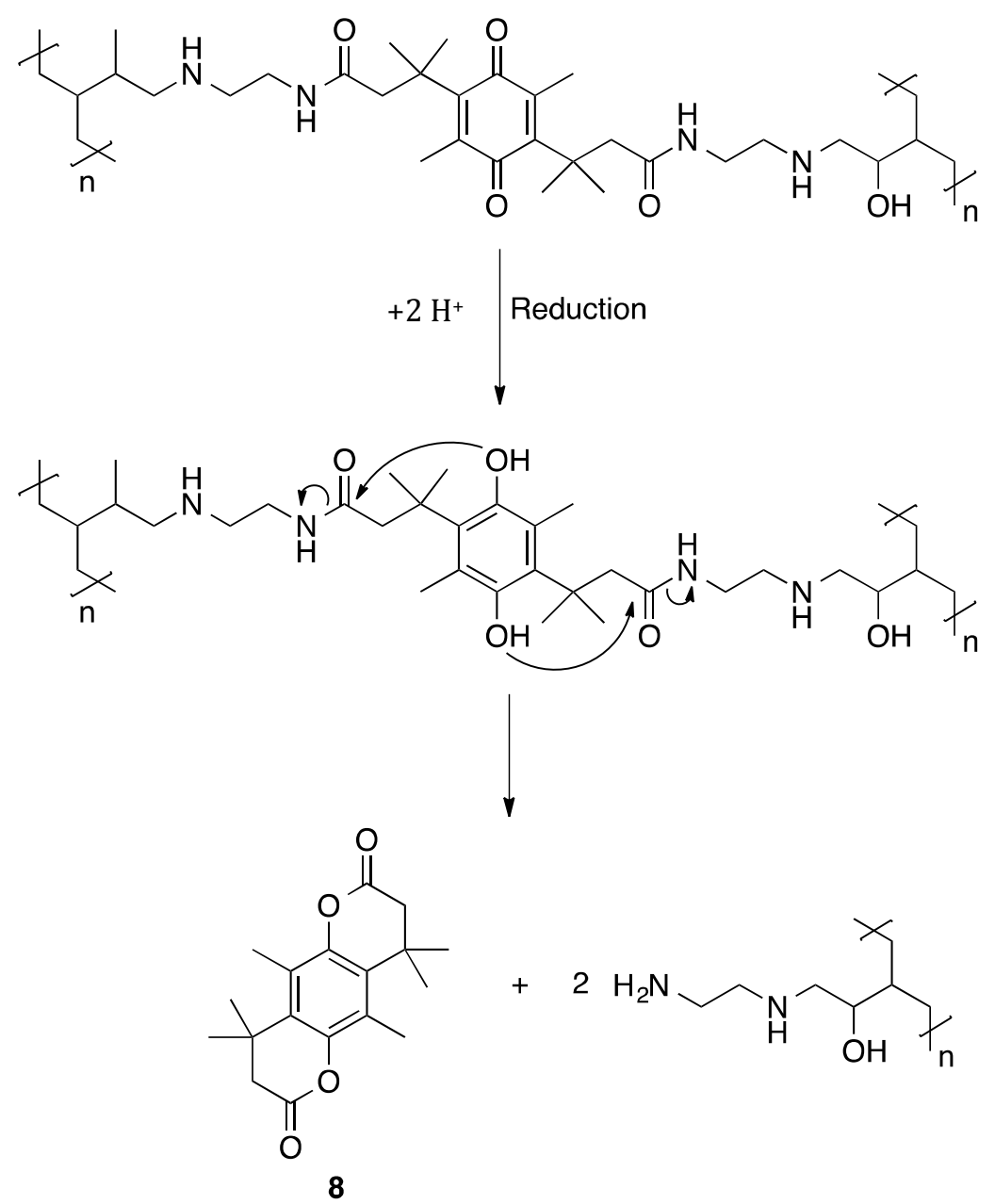

Figure 11. Reductive degradation of crosslinked polymer via hardener 4 to lactone $\mathbf{8}$ and corresponding amine attached to polymer.

The application of an electrical current should be sufficient to reduce the quinone of the crosslinked compound to the unstable hydroquinone to de-bond these crosslinkers. The application of this electrical current may not be able to penetrate past the surface of the adhesive. In this case, polymer doping may be necessary to help facilitate the distribution of electrons throughout the adhesive. Polymer doping can be achieved by adding an electron carrier and electrolyte solution. An example of these would be 
ruthenium-tris(2,2'-bipyridyl) dichloride as an electron carrier and lithium perchlorate as a supporting electrolyte. These doping agents have been successfully used in past works in the d'Alarcao group with divinyl benzene EDCR crosslinked with polystyrene beads. ${ }^{35}$ In most applications the surface of the adhesive in contact with the adhered components is what is essential for de-bonding to take place, depending on how well an electrical current is dispersed throughout the adhesive, which will determine the necessity of polymer doping to be used. Once de-bonding takes place, the adhesive would then be able to be wiped away. 


\section{CHAPTER 3}

\section{RESULTS AND DISCUSSION}

\subsection{DIAMINE EPOXIDE CROSSLINKING EDCR}

Two diamine EDCRs were synthesized to crosslink polymers with epoxide functional groups. Both EDCRs have identical core structures and were designed in parallel. All new compounds prepared in this work were characterized using ${ }^{1} \mathrm{H}$ NMR and mass spectrometry. EDCRs $\mathbf{4}$ and $\mathbf{5}$ were both synthesized from the di-acid $\mathbf{9}$ previously made by the d'Alarcao group. ${ }^{36}$ The same procedures were followed in synthesizing 9 except for a modification of the reaction for synthesizing lactone $\mathbf{8}$ from compound 6. Scheme 2 shows the modified reaction of 2,5-dimethylhydroquinone with methyl-3-methylbutenoate in methanesulfonic acid at $80{ }^{\circ} \mathrm{C}$ to produce the lactone 8 . In this reaction, 2 molar equivalents of methyl-3-methylbutenoate were added dropwise over $1 \mathrm{~h}$ and allowed to react for $5 \mathrm{~h}$. This was followed by dropwise addition of another 2 molar equivalents of methyl-3-methylbutenoate, and an additional $15 \mathrm{~h}$ of reaction.

Scheme 2: Acylation reaction of 2,5-dimethylhydroquinone 6 with methyl-3-methylbutenoate 7.<smiles>COC(=O)C=C(C)C</smiles> 


\subsubsection{SYNTHESIS OF 4}

The construction of EDCR $\mathbf{4}$ starts by constructing the amine arms that will be coupled with the di-acid 9 . Ethylenediamine was mono-Boc protected following literature procedures to give compound $\mathbf{1 0} .^{37}$ The coupling of the amine arms with the diacid is depicted in Scheme 3. The di-acid $\mathbf{9}$ was dissolved in acetonitrile and added to along with $1 / 4$ equivalent hydroxybenzotriazole (HOBt), 2.2 equivalents 1-ethyl-3-(3dimethylaminopropyl)carbodiimide (EDC) and the solution was let to stir. Next, a mixture of 2.5 equivalents of $\mathbf{1 0}$ and 2.5 equivalents of triethylamine in acetonitrile was added to the reaction and let to react overnight. The solvent was evaporated and the residue was then dissolved in ethyl acetate and washed with $1 \mathrm{M} \mathrm{HCl}$ followed by water and brine, the organic layer wash dried using magnesium sulfate and then purified using flash chromatography, giving $\mathbf{1 1}$ in a 68\% yield. ${ }^{38}$ Lastly, $\mathbf{1 1}$ was deprotected using $6 \mathrm{M}$ $\mathrm{HCl}$ and equal volume methylene chloride to remove the Boc groups, giving the protonated version of hardener 4 . The protonated form (20) was verified using ${ }^{1} \mathrm{H}$ NMR, but efforts to deprotonate the molecule were unsuccessful, probably due to rapid reaction of the free amine. 
Scheme 3: Synthesis of hardener 4 from compound 9.

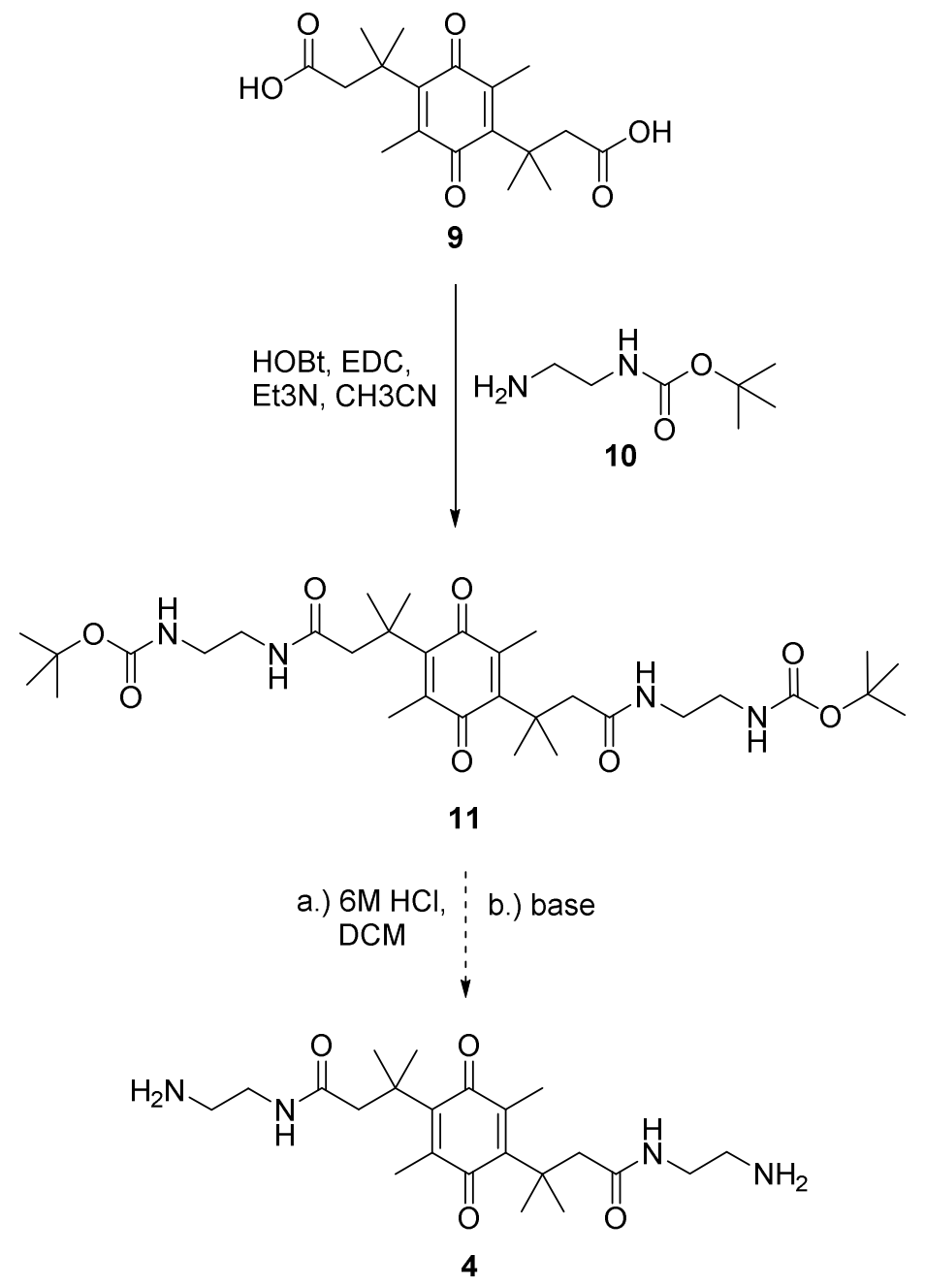

Deprotonation was attempted by increasing the $\mathrm{pH}$ to $>10$ using sodium hydroxide. ${ }^{1} \mathrm{H}-\mathrm{NMR}$ indicated a mixture of multiple compounds, none of which were able to be purified. Past studies have shown degradation of a similar compound upon exposure to acidic or alkali conditions. ${ }^{40}$ The hydroxypropyl-p-benzoquinone compound shown in Figure 12 is a stable compound in neutral conditions, but when exposed to basic conditions of a $\mathrm{pH}>10$, an intramolecular conjugate addition occurs where the 
nucleophilic alcohol attacks the alpha carbon on the quinone, forming a five membered ring. When the hydroxypropyl-p-benzoquinone is introduced to acidic conditions of $<2$, then the nucleophilic alcohol attacks the carbon of the carbonyl on the quinone, which produces an unstable six membered ring that quickly undergoes elimination/addition reactions. Hardener $\mathbf{4}$ may undergo similar intramolecular conjugate addition reactions when it is exposed to basic conditions upon deprotonation and the amine may act as a nucleophile in a similar fashion as the alcohol in Figure 12, forming an eight membered ring, which is depicted in Figure 13. However, this process remains speculation since NMR after deprotonation indicated a combination of multiple compounds, none of which were able to be identified.

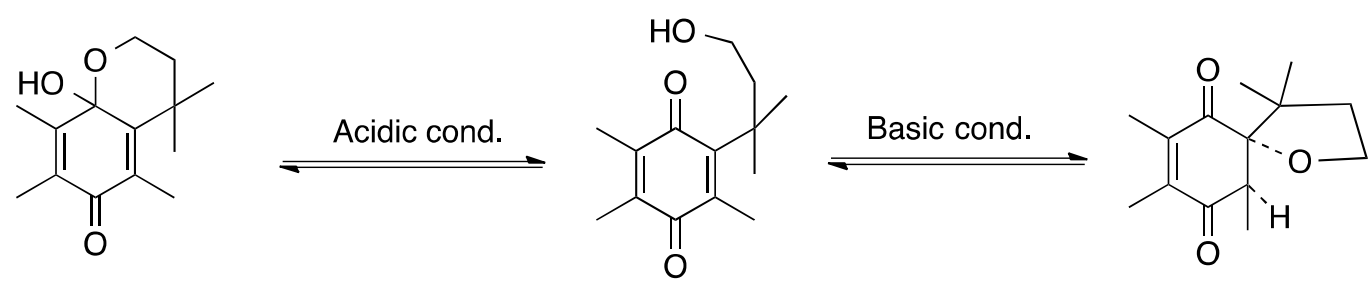

Figure 12. Intramolecular conjugate addiction reactions of hydroxypropyl-pbenzoquinone under acidic and alkali conditions. 


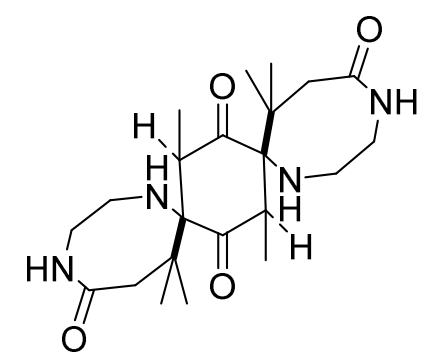

Figure 13. Proposed product of hardener $\mathbf{4}$ after deprotection of the amines forming eight membered rings.

\subsubsection{SYNTHESIS OF HARDENER 5}

The formation of hardener $\mathbf{5}$ is similar to that of $\mathbf{4}$. The main difference is in the amine arm used in the coupling with compound $\mathbf{9}$. The synthesis of the Boc-protected amine arm is shown in Scheme 4, and the synthesis of hardener 5 is shown in Scheme 5. To make the protected amine arm, 1,4-phenylenediacetonitrile was reduced to the diamine. 1,4-Phenylenediacetonitrile was dissolved in 7M ammoniated methanol in a hydrogenation flask, then Raney nickel was added and the flask was fitted to a Parr hydrogenator and pressurized with $\mathrm{H}_{2}$ to about 50 psi and shaken for 4 days, repressurizing when needed. ${ }^{45}$ Once all the nitrile groups were reduced, as indicated by cessation of $\mathrm{H}_{2}$ pressure reduction, the solution was filtered to remove the Raney nickel and the solvent evaporated. Next, the diamine $\mathbf{1 3}$ was Boc protected in similar fashion to that of compound $\mathbf{1 0}$, six equivalents of $\mathbf{1 3}$ was dissolved in methanol and stirred, then 1 equivalent of di-tert-butyl-dicarbonate $\left(\mathrm{Boc}_{2} \mathrm{O}\right)$ in methanol was added dropwise to the stirring solution and let to react overnight. The solvent was evaporated and the product dissolved in water. The solution was filtered, leaving behind the insoluble di-protected product, and the aqueous layer was shaken with methylene chloride to extract the mono- 
Boc protected product into the organic layer, leaving behind any starting material in the aqueous layer. The organic layer was dried with magnesium sulfate and concentrated in vacuo giving compound $\mathbf{1 3}$ in a $99 \%$ yield based on $\mathrm{Boc}_{2} \mathrm{O} .{ }^{37}$

Scheme 4: Synthesis of Boc protected amine arm for formation of compound 5.
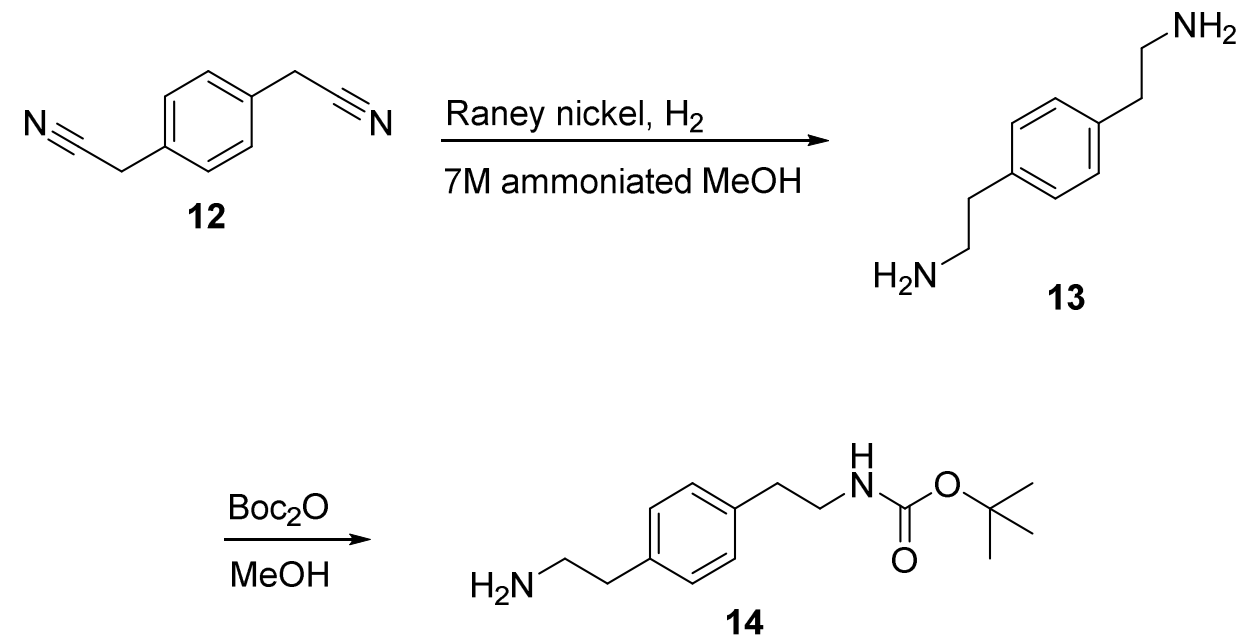

Compound $\mathbf{1 4}$ was coupled with the di-acid $\mathbf{9}$ in the same fashion as described earlier for synthesis of compound 11, with a yield of $40 \%$ (Scheme 5). A Boc deprotection was attempted following the same procedures as for hardener $\mathbf{4}$, but no removal of the Boc groups was achieved. To avoid subjecting this molecule to overly acidic conditions, other routes of deprotection should be investigated; one option would be the use of TFA, which is commonly used in the deprotection of Boc groups. ${ }^{39}$ 
Scheme 5: Synthesis of hardener 5 from compound 9.

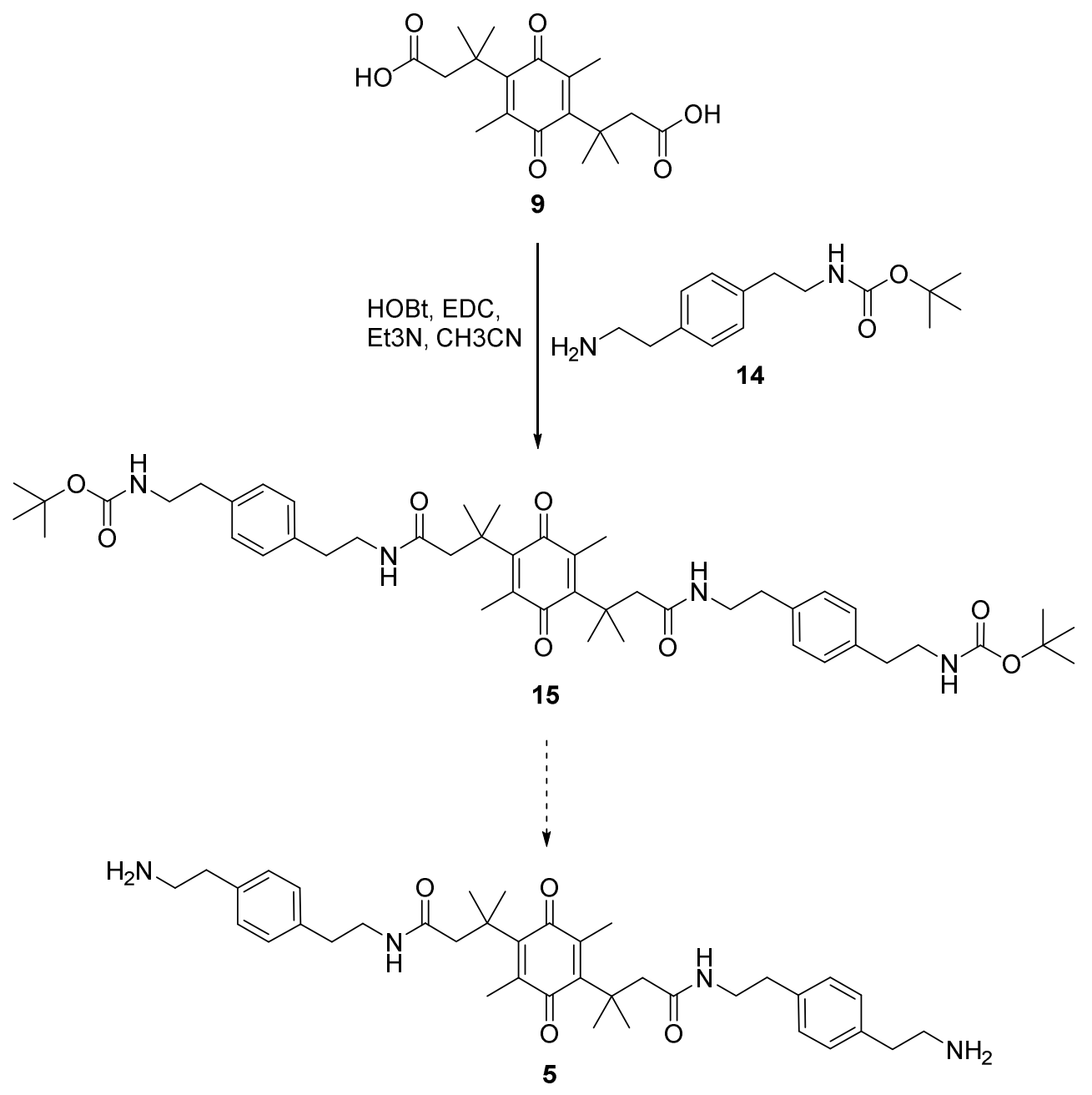




\section{CHAPTER 4}

\section{CONCLUSION AND FUTURE GOALS}

\subsection{CONCLUSION}

At this point, compounds $\mathbf{1 5}$ and the protonated form of $\mathbf{4}$ have been synthesized and characterized by ${ }^{1} \mathrm{H}$ NMR. Synthesizing hardener $\mathbf{4}$ involves using acid to deprotect the Boc groups on compound 11, which leaves the two terminal amines on hardener 4 protonated. The protonated form was verified as expected using ${ }^{1} \mathrm{H}$ NMR. Sodium hydroxide was used to deprotonate the primary amines by bringing the $\mathrm{pH}$ to $>10$. The ensuing NMR spectrum revealed a mixture of compounds, none of which were able to be identified or purified. It is likely that an intramolecular conjugate addition took place, similar to the hydroxypropyl-p-benzoquinone in Figure 12, with the nucleophilic amines acting similar to the alcohol in Figure 12 under basic conditions. This result is what led to the design of the amine arms for hardener 5 with phenyl groups. If, in hardener $\mathbf{4}$, the deprotonated arms are too close to electrophilic groups on the quinone, then modification of the arms so that the terminal amines are not in proximity to these groups is desirable. Phenyl groups were inserted between the amide and terminal amine for two purposes: so that the phenyl group would straighten the arms, keeping the amines away from the core of the molecule, and so that it would also lengthen the arms, furthering the distance between the amines and the rest of the molecule. Compound 15 was synthesized and verified using ${ }^{1} \mathrm{H}$ NMR, but has yet to be deprotected; the compound was found to be stable under acid conditions when it came to deprotection of the Boc groups, relative to 
compound 11. Other deprotection methods that can more easily remove the Boc groups without destroying the rest of the molecule are being investigated.

\subsubsection{FUTURE STUDIES}

Still left to be completed is NMR analysis of the degradation products of hardener 4 upon deprotonation of the terminal amines. Slowly adding base to a solution of the protonated form of $\mathbf{4}$ and taking ${ }^{1} \mathrm{H}$ NMR scans at regular intervals should reveal the products of degradation and give some hint as to how long the compound is stable once unprotonated. With this information, a protocol will be developed to study the crosslinking of a commercially available epoxy resin. Past tests have shown that ethylenediamine has successfully hardened with a commercially available epoxy resin. This verifies that if successfully synthesized, hardeners $\mathbf{4}$ and $\mathbf{5}$ should be able to do the same and harden an epoxy resin.

Compound 15 needs to be deprotected to become hardener 5. A reaction using $6 \mathrm{M} \mathrm{HCl}$ and equal volume methylene chloride was unable to deprotect the Boc groups, leaving the compound in the organic layer. Therefore, a new method needs to be devised in the deprotection reaction. A common method for deprotection of Boc groups is TFA. Following literature procedures, a 1:1 solution of TFA and methylene chloride will be allowed to react for $1 \mathrm{~h}$. With the insertion of the phenyl groups in the arms of hardener, once the terminal amines are deprotonated giving $\mathbf{5}$, the compound should be stable long enough to obtain ${ }^{1} \mathrm{H}$ NMR and MS. Once hardener $\mathbf{5}$ is synthesized then degradation studies can be performed. This is done by having an NMR tube with hardener $\mathbf{5}$ and adding a reducing agent to it and taking ${ }^{1} \mathrm{H}$ NMR scans at regular intervals. What should 
be seen is peaks representing $\mathbf{5}$ disappearing as peaks for lactone $\mathbf{8}$ and diamine $\mathbf{1 3}$ increase, similar to what is depicted in Figure 7. Once it is confirmed that reduction of

the quinone to the unstable intermediate hydroquinone of $\mathbf{5}$ causes cleavage of the amides forming lactone $\mathbf{8}$ and respective diamines, then it can be tested as a hardener by mixing with an epoxy resin and comparing its level of adhesion to that of a commercially available hardener. An instrument to test the tensile strength of the adhesive would tell us the equivalent adhesive strength relative to a commercially available hardener. Tensile strength is the maximum pulling force a material can withstand before failing. If either or both compounds $\mathbf{4}$ and $\mathbf{5}$ are able to successfully act as a hardener, then the next steps would be to test the ability of the hardened epoxy resin to de-bond following the application of an electrical current. If total de-adhesion is not successful, then we can investigate whether or not the addition of an electron carrier and electrolyte solution is necessary in aiding in the de-adhesion process. Not all of the adhesive needs to de-bond, only the parts in contact with the objects being adhered.

\subsection{FUTURE APPLICATIONS}

Having an on-demand reversible adhesive would be advantageous in numerous settings. Since degradation would be achieved with the application of an electrical current, there is very little possibility of unwanted de-adhesion. This new technology would be very beneficial for a manufacturing setting where a percentage of products that have a component glued on are mis-adhered, which could be reused rather than discarded. For example, the glass face on a smart phone is glued on. If it is attached incorrectly, that phone which is near the end of the production line is thrown away. If 
our reversible adhesive were used, then all that needs to be done is to have a low voltage current applied, which would de-adhere the glass cover; the de-bonded adhesive would be wiped off and the glass face re-adhered.

In other cases, it would be advantageous for a component of a product to be removed at a different time in the life of the product. Many laptops have batteries which are glued, rather than screwed, onto the frame of the computer, which allows the laptop to be thinner. If the battery becomes damaged, the laptop would need to be replaced since the battery cannot be removed. In addition, due to potential environmental harm, batteries must be recycled. If the battery is fixed permanently to the computer, it cannot be properly recycled. With this reversible adhesive, these batteries would be able to be removed, replaced, and recycled properly. There are a plethora of applications for a reversible adhesive. 


\section{CHAPTER 5}

\section{EXPERIMENTAL PROCEDURES}

General Methods. All solvents and reagents were purchased from commercial sources (Fisher Scientific or Sigma Aldrich) and were used without further purification unless otherwise stated. Deionized (DI) water was used in reactions where water was mentioned. Organic extracts were dried using anhydrous magnesium sulfate and then vacuum filtered. All solvents were evaporated in vacuo on a rotary evaporator at 10-15 Torr and $36^{\circ} \mathrm{C}$. Reaction monitoring was done using thin layer chromatography (TLC) on Baker glass-backed silica gel plates $(0.25-\mathrm{mm}$ thickness) with a 254-nm fluorescent indicator. Compounds were visualized by ultraviolet illumination. Separations were performed by flash chromatography on Baker silica gel (particle size 40-50 nm). NMR data for ${ }^{1} \mathrm{H}$ were obtained on an Inova-400 MHz spectrometer and reported in parts per million ( $\delta$ ). High-resolution MS data was obtained using an electrospray ionization MS(ESI-MS).

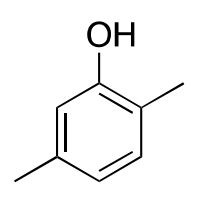

16

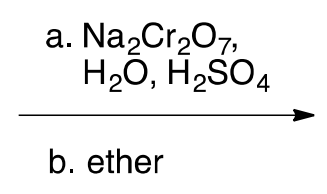

b. ether<smiles>CC1=CC(=O)C(C)=CC1=O</smiles>

17

Figure 14. 2,5-Dimethylquinone synthesis. 
2,5-Dimethylquinone (17). ${ }^{40}$ The Jones reagent was prepared by dissolving sodium dichromate $(165 \mathrm{~g})$ in water $(235 \mathrm{~mL})$ and chilling the solution to $0{ }^{\circ} \mathrm{C}$ in an ice bath. Sulfuric acid (105 mL) was added dropwise, turning the solution dark orange. Next, compound 16 (30 g) was dissolved in ether $(350 \mathrm{~mL})$ in a 3-necked round bottom flask fitted with an addition funnel, a condenser, and an overhead mechanical stirrer. The round bottom flask was submerged in an ice bath, and the Jones reagent was added dropwise through the addition funnel over a period of $3 \mathrm{~h}$. Afterwards, the addition funnel was removed and the reaction allowed to react for $48 \mathrm{~h}$ at room temperature. The solution turned dark green and was highly viscous. The solution was then washed with ether $(4 \times 400 \mathrm{~mL})$ and additional water $(700 \mathrm{~mL})$ was used to encourage separation. The organic layer was washed with saturated sodium bicarbonate $(2 \times 100 \mathrm{~mL})$ and water $(200$ $\mathrm{mL}$ ), then dried with magnesium sulfate and the solvent evaporated. The orange crude product was purified by repeated recrystallization from hot ethanol giving compound $\mathbf{1 7}$ (11.54 g, 34.04\% yield). [ $\mathrm{R}_{\mathrm{f}}=0.6$ (methylene chloride).<smiles>CC1=CC(=O)C(C)=CC1=O</smiles>

17

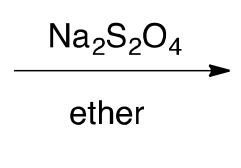

Figure 15. 2,5-Dimethylhydroquinone synthesis. 
2,5-Dimethylhydroquinone (6). ${ }^{41}$ Compound 17 (10.65 g) was dissolved in ether (420 $\mathrm{mL}$ ), forming an orange solution. This solution was shaken with freshly prepared saturated aqueous sodium dithionate $(840 \mathrm{~mL})$ in a separatory funnel until the orange color turned to a pale yellow color. The organic layer was then washed with water (300 $\mathrm{mL})$, dried with magnesium sulfate, and evaporated, giving a pale yellow powder $(8.44 \mathrm{~g}$, $78.3 \%$ yield). $\left[\mathrm{R}_{\mathrm{f}}=0.1\right.$ (methylene chloride) $]$.<smiles>CC(C)=CC(=O)O</smiles>

18

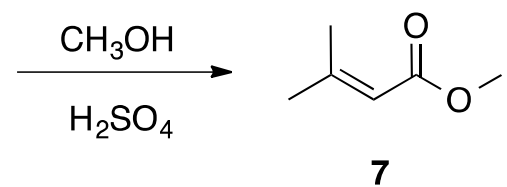

7

Figure 16. Methyl-3-methylbutenoate synthesis.

Methyl-3-methylbutenoate (7). ${ }^{\mathbf{4 2}}$ Compound $\mathbf{1 8}$ (36 g) was dissolved in methanol (200 $\mathrm{mL})$ with constant stirring while sulfuric acid $(10 \mathrm{~mL})$ was added. The yellow solution was refluxed under nitrogen for $2 \mathrm{~h}$ at $70{ }^{\circ} \mathrm{C}$. After this, the reaction was cooled to room temperature and water $(240 \mathrm{~mL})$ was added and extracted with ether $(4 \times 100 \mathrm{~mL})$. The organic layer was then washed with saturated sodium bicarbonate $(3 \times 100 \mathrm{~mL})$ and water $(2 \times 100 \mathrm{~mL})$, followed by saturated sodium chloride $(100 \mathrm{~mL})$, then dried using magnesium sulfate and the solvent evaporated off. The resulting colorless liquid product was purified via distillation (between $\left.120-125^{\circ} \mathrm{C}\right)\left(29.05 \mathrm{~g}, 70.8 \%\right.$ yield). $\left[\mathrm{R}_{\mathrm{f}}=0.16(3: 1\right.$ hexane/ethyl acetate); ${ }^{1} \mathrm{H} \mathrm{NMR}\left(400 \mathrm{MHz}, \mathrm{CDCl}_{3}\right): \delta(\mathrm{ppm}) 5.55(\mathrm{~s}, 1 \mathrm{H}, \mathrm{CH}), 3.53(\mathrm{~s}, 3 \mathrm{H}$, $\left.\mathrm{CH}_{3}\right), 2.07$ (s, 3H, $\left.\left.\mathrm{CH}_{3}\right), 1.78\left(\mathrm{~s}, 3 \mathrm{H}, \mathrm{CH}_{3}\right)\right]$. 


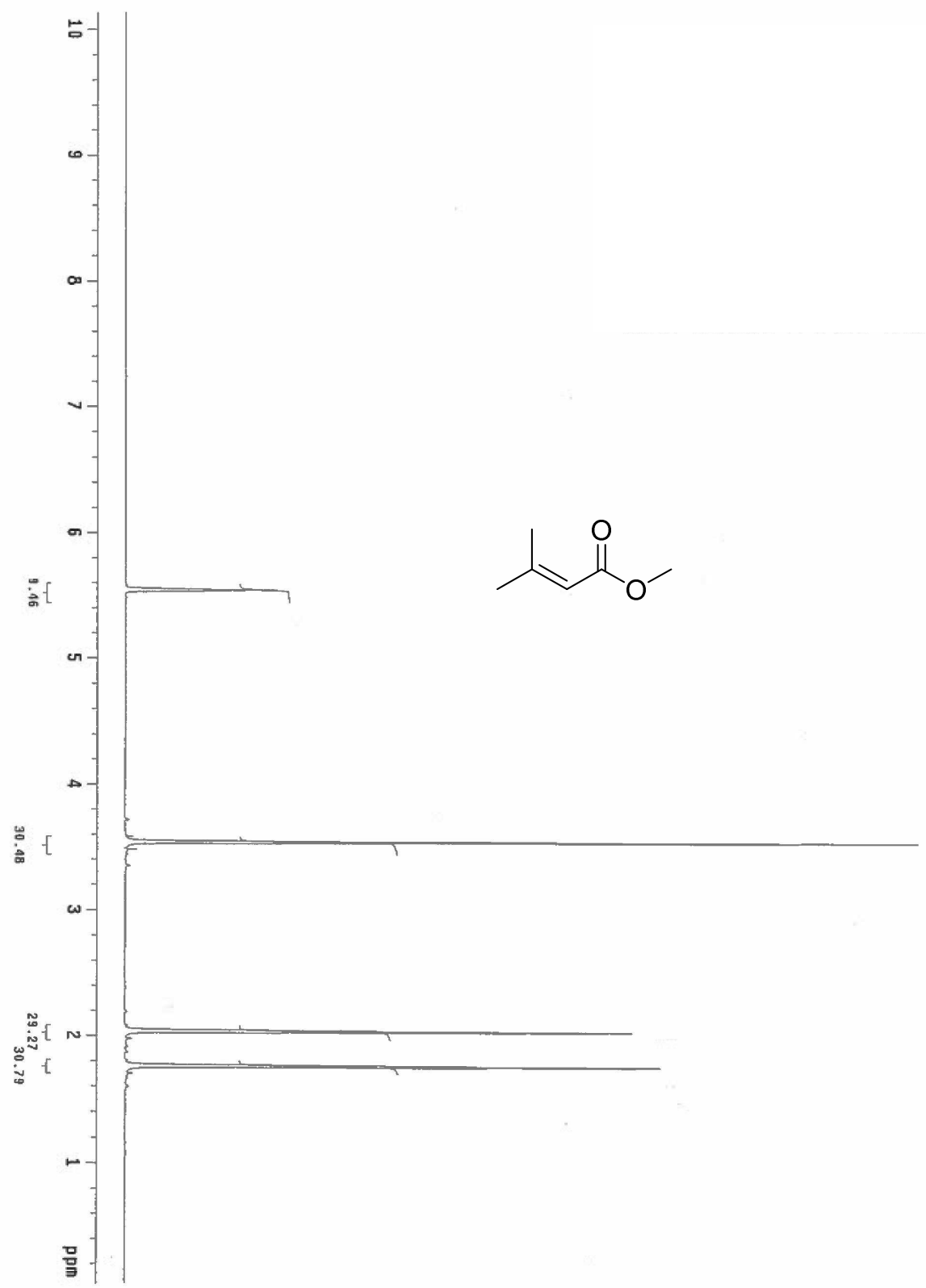

Figure 17. ${ }^{1} \mathrm{H}$ NMR spectra of methyl-3-methylbutenoate in deuterated chloroform (7). 


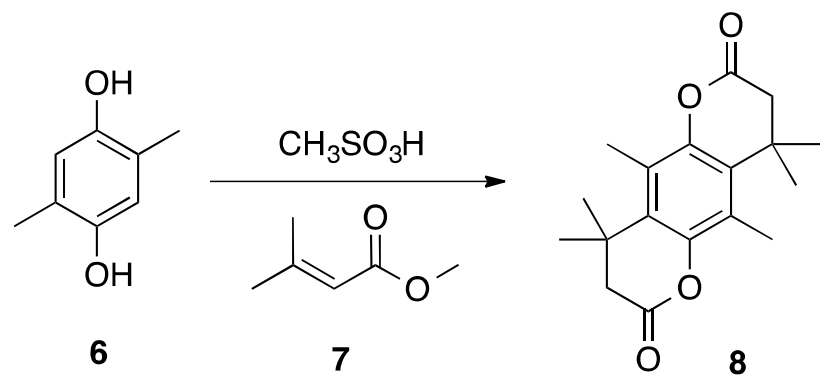

Figure 18. 4,8-Dihydro-9,10-dimethyl-1,5-dioxa-3,3,7,7-tetramethyl-2,6anthraquinone synthesis.

\section{4,8-Dihydro-9,10-dimethyl-1,5-dioxa-3,3,7,7-tetramethyl-2,6-anthraquinone (8).}

Compound $\mathbf{6}^{35}$ (3.30g, 0.0239 mols, 1 eq.) was dissolved in $25 \mathrm{ml}$ of methanesulfonic acid then heated in an oil bath to $80^{\circ} \mathrm{C}$ under nitrogen with a reflux condenser attached. Once heated to $80^{\circ} \mathrm{C}$ compound $4(5.30 \mathrm{~mL}, 0.0464 \mathrm{mols}, 2$ eq.) was added dropwise over the period of $1 \mathrm{~h}$, then left to react for $5 \mathrm{~h}$. Subsequently another 2 eq. was added, again dropwise over the period of $1 \mathrm{~h}$, then let to react for $15 \mathrm{~h}$. After this, the reaction was quenched by pouring the solution over $600 \mathrm{~mL}$ of ice water. Then the solution was extracted using ethyl acetate $(4 \times 150 \mathrm{~mL})$. The organic layer was washed with sodium bicarbonate $(3 \times 200 \mathrm{~mL})$, followed by DI water $(3 \times 100 \mathrm{~mL})$ and a brine solution $(2 \times 150$ $\mathrm{mL}$ ), then dried using magnesium sulfate, filtered, and concentrated in vacuo, yielding $(12.15 \mathrm{~g})$ a dark yellow solution. The monoacylated byproduct was separated by dissolving the product in methylene chloride $(200 \mathrm{~mL})$ and washed with sodium hydroxide $(2 \times 200 \mathrm{~mL})$, followed by ammonium chloride $(2 \times 200 \mathrm{~mL})$ and water $(2 \times 200$ $\mathrm{mL}$ ), then dried with magnesium sulfate, and the solvent evaporated. The product was purified by repeated recrystallization from hot ethanol yielding ( $3.03 \mathrm{~g}, 41.9 \%$ yield) of 
the lactone 8 , a white powder. $\left[\mathrm{R}_{\mathrm{f}}=0.33\right.$ (methylene chloride); ${ }^{1} \mathrm{H}$ NMR $(400 \mathrm{MHz}$, $\left.\left.\mathrm{CDCl}_{3}\right): \delta(\mathrm{ppm}) 2.55\left(\mathrm{~s}, 4 \mathrm{H}, \mathrm{CH}_{2}\right), 2.38\left(\mathrm{~s}, 6 \mathrm{H}, \mathrm{CH}_{3}\right), 1.42\left(\mathrm{~s}, 12 \mathrm{H}, \mathrm{CH}_{3}\right)\right]$.

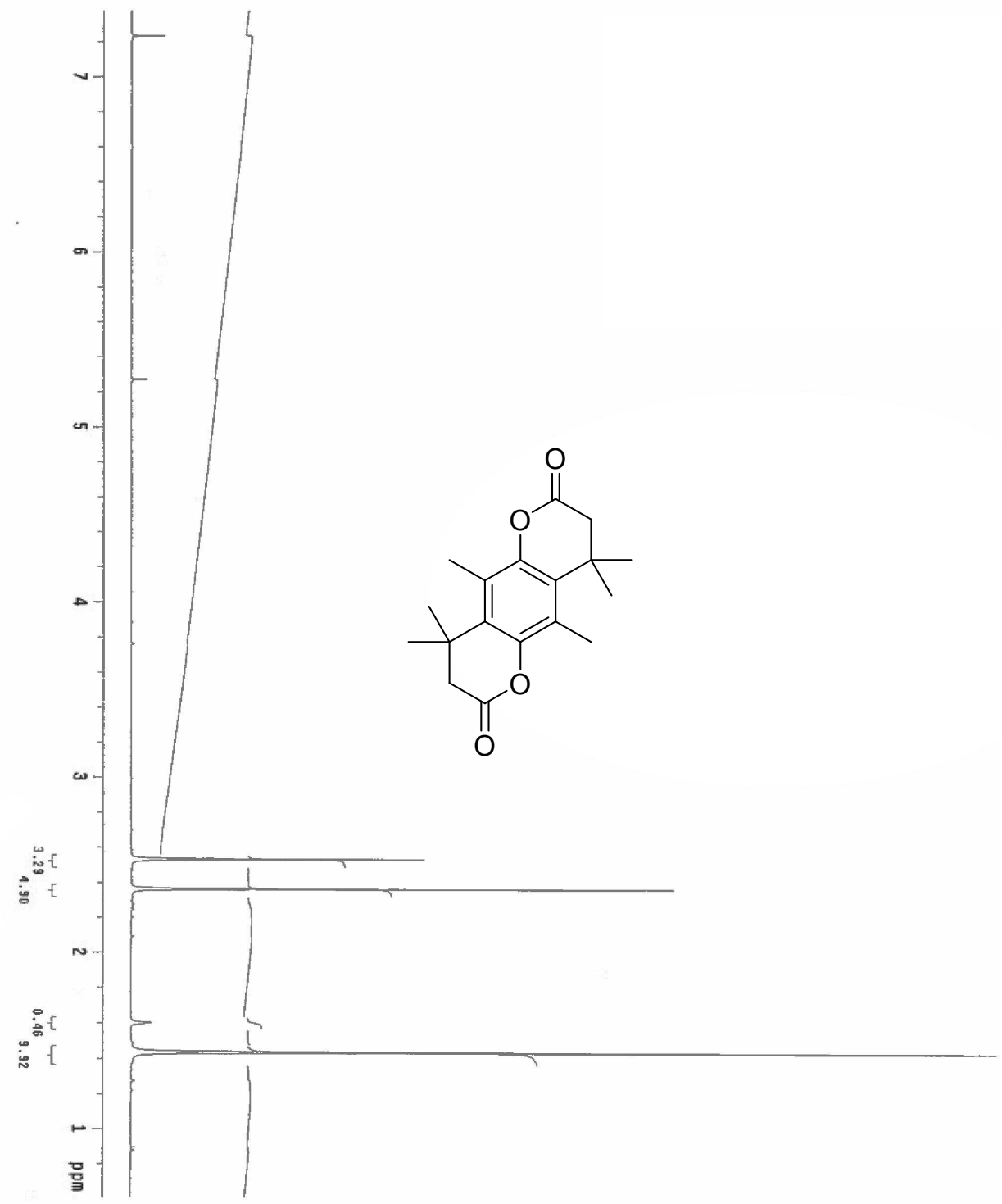

Figure 19. ${ }^{1} \mathrm{H}$ NMR spectra of 4,8-dihydro-9,10-dimethyl-1,5-dioxa-3,3,7,7tetramethyl-2,6-anthraquinone in deuterated chloroform (8). 

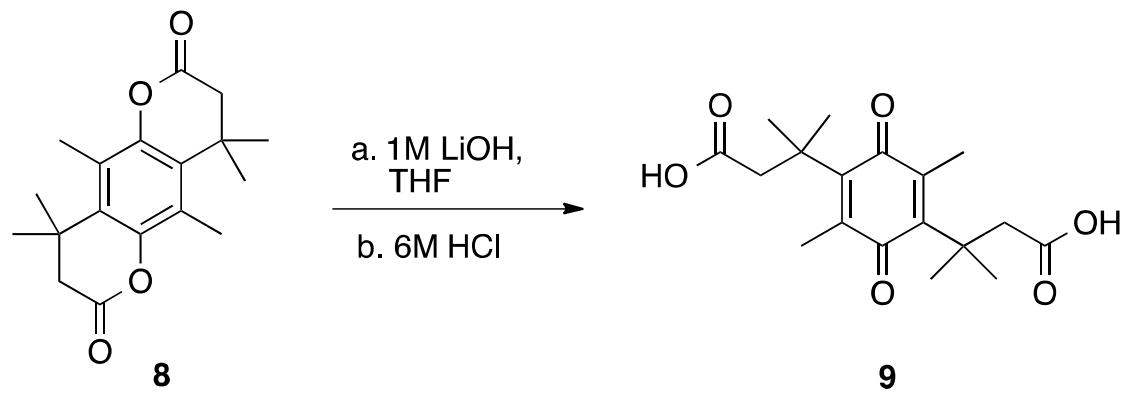

Figure 20. 1,4-Bis(1,1-dimethyl-3-propanoic acid)-2,5-dimethylquinone synthesis.

\section{1,4-Bis(1,1-dimethyl-3-propanoic acid)-2,5-dimethylquinone (9). ${ }^{\mathbf{3 4}}$ Lactone 8 (0.09 g)} was dissolved in THF $(9 \mathrm{~mL})$ then $1 \mathrm{M} \mathrm{LiOH}(9.3 \mathrm{~mL})$ was added and let to stir uncapped for $5 \mathrm{~h}$. Next, $6 \mathrm{M} \mathrm{HCl}$ was added dropwise until the $\mathrm{pH}$ reached 3, then extracted using ethyl acetate $(2 \times 35 \mathrm{~mL})$ after the addition of water $(10 \mathrm{~mL})$ to encourage separation. The organic layer was then washed with water $(10 \mathrm{~mL})$ and saturated sodium chloride $(10$ $\mathrm{mL}$ ), the organic layer was dried using magnesium sulfate, and the solvent evaporated giving a yellow solid $(0.11 \mathrm{~g}, 100 \%$ yield $) . \quad\left[\mathrm{R}_{\mathrm{f}}=0\right.$ (methylene chloride); HRMS (ESI): calcd for $\mathrm{C}_{18} \mathrm{H}_{24} \mathrm{O}_{6}[\mathrm{M}-\mathrm{H}]^{-}$335.1573; found 335.2004]. 


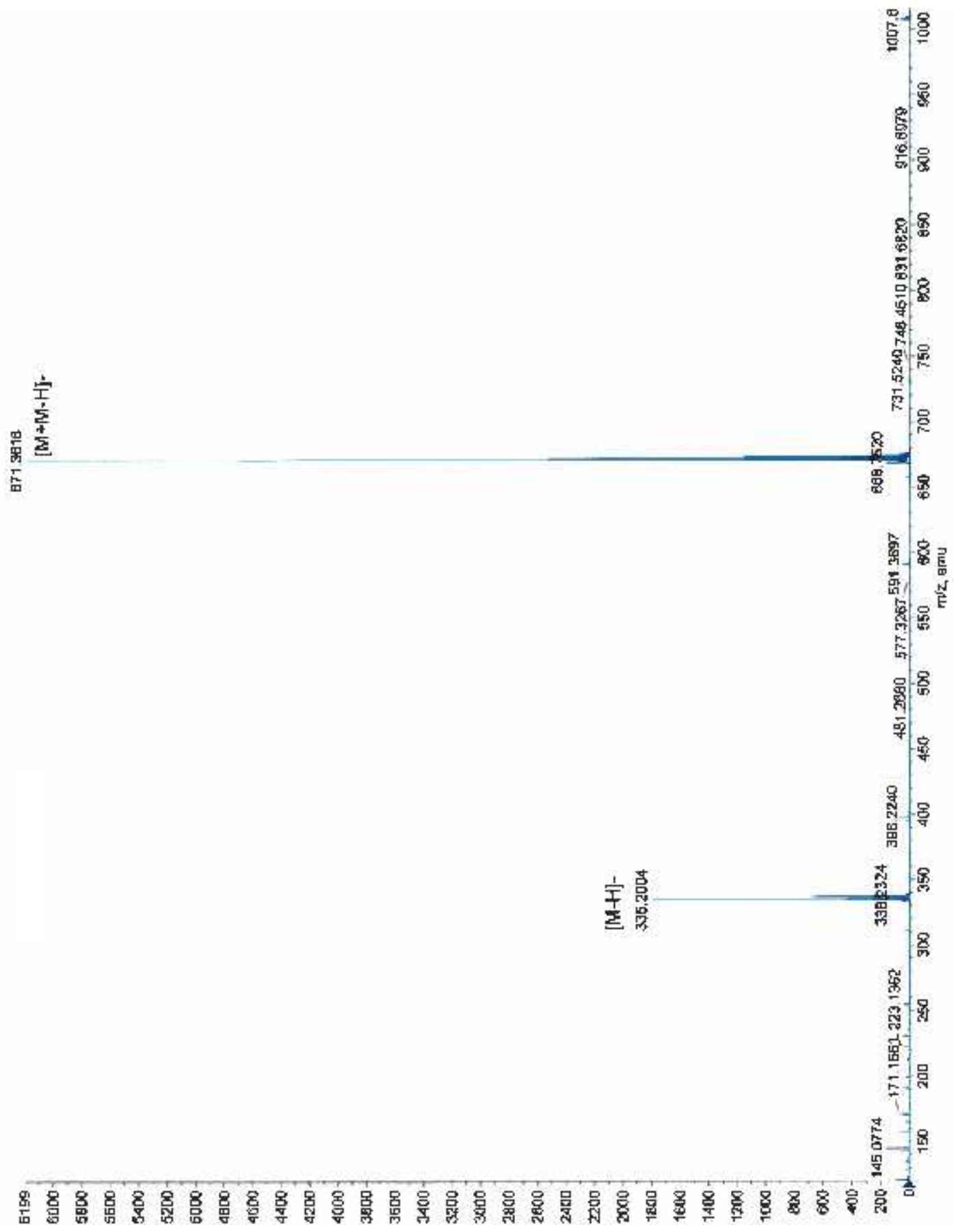

Figure 21. Mass Spectra of 1,4-Bis(1,1-dimethyl-3-propanoic acid)-2,5dimethylquinone. 


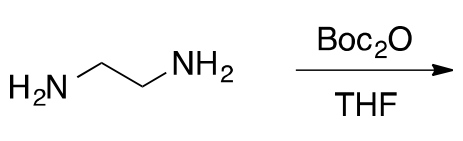

19

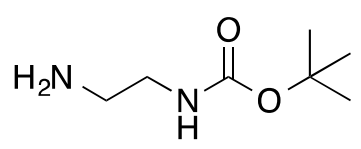

10

Figure 22. tert-Butyl (2-aminoethyl)carbamate synthesis.

tert-Butyl (2-aminoethyl)carbamate (10). ${ }^{37}$ A solution of $\mathrm{Boc}_{2} \mathrm{O}(1.703 \mathrm{~g}, 7.803 \mathrm{mmols}$, 1 eq.) in THF ( $20 \mathrm{~mL}$ ) was added dropwise to a stirring solution of Ethylenediamine (16) (3.13 mL, $46.8 \mathrm{mmols}, 6$ eq.) in THF $(20 \mathrm{~mL})$ at $0{ }^{\circ} \mathrm{C}$ over a period of $1 \mathrm{~h}$, then let to reacted overnight at room temperature. The solvent evaporated and the product was dissolved in DI water $(200 \mathrm{~mL})$ and solution was vacuum filtered. The aqueous solution was extracted using methylene chloride $(3 \times 150 \mathrm{~mL})$, then dried using magnesium sulfate and the solvent evaporated off, giving a clear liquid, $10(0.796 \mathrm{~g}, 63.7 \%$ yield $) .\left[\mathrm{R}_{\mathrm{f}}=\right.$ 0.10 (1:1 methylene chloride/ethyl acetate); HRMS (ESI): calcd for $\mathrm{C}_{7} \mathrm{H}_{16} \mathrm{~N}_{2} \mathrm{O}_{2}[\mathrm{M}+\mathrm{H}]^{+}$ 161.1212; found 161.1436]. 


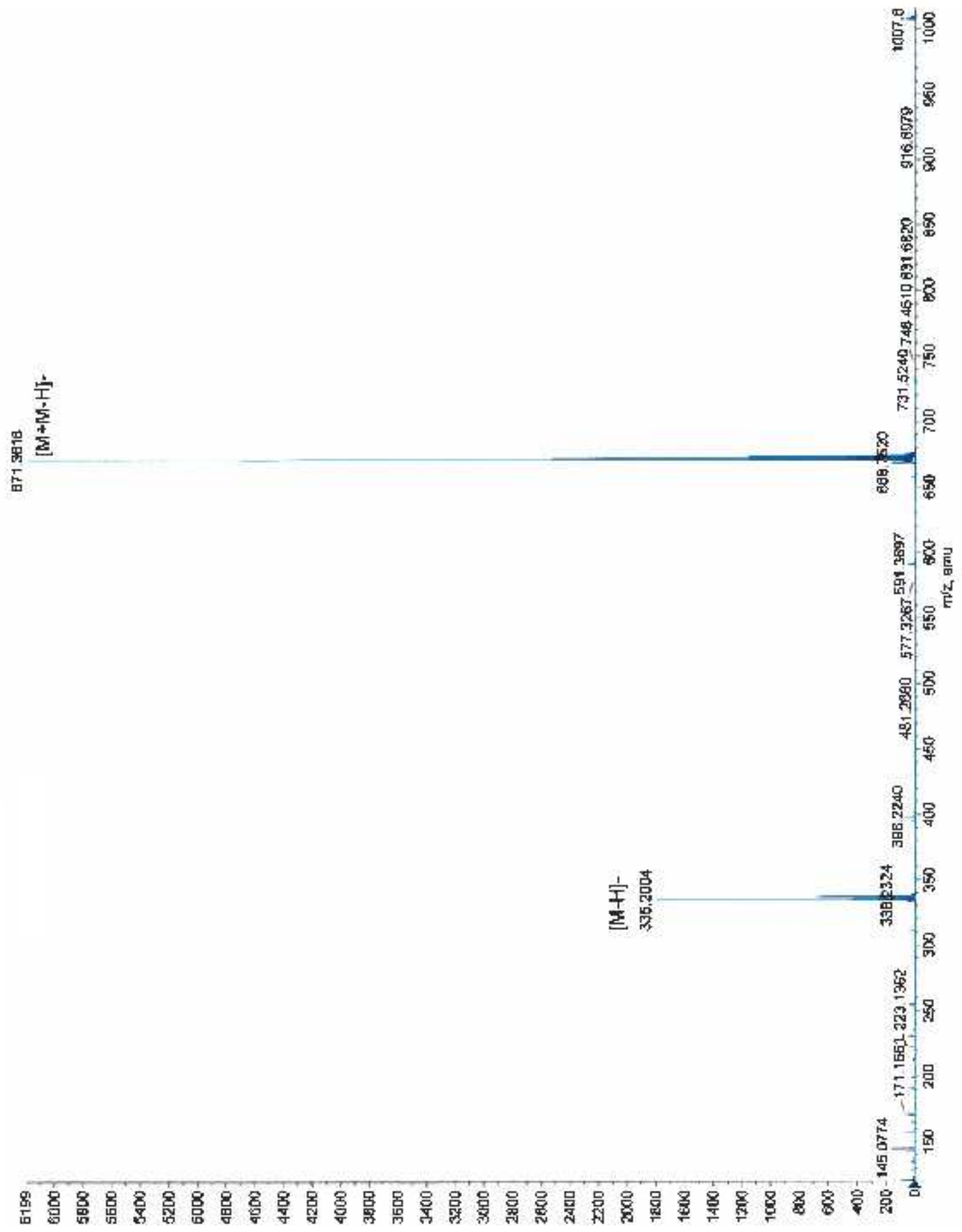

Figure 23. Mass spectra of tert-butyl (2-aminoethyl)carbamate. 
<smiles>CC1=C(C(C)(C)CC(=O)O)C(=O)C(C(C)(C)CC(=O)O)=C(C)C1=O</smiles>

9

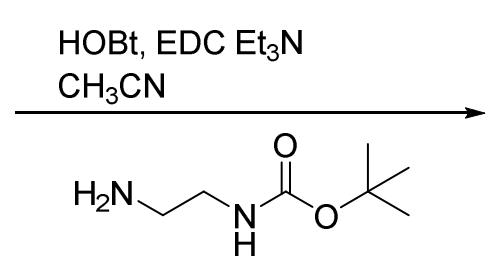

10<smiles>CC1=C(C(C)(C)CC(=O)NCCNC(=O)OC(C)(C)C)C(=O)C(C)=C(C(C)(C)CC(=O)NCCNC(=O)OC(C)(C)C)C1=O</smiles>

11

Figure 24. Di-tert-butyl (((3,3'-(2,5-dimethyl-3,6-dioxocyclohexa-1,4-diene-1,4diyl)bis(3-methylbutanoyl))bis(azanediyl))bis(ethane-2,1-diyl))dicarbamate synthesis.

\section{Di-tert-butyl (((3,3'-(2,5-dimethyl-3,6-dioxocyclohexa-1,4-diene-1,4-diyl)bis(3-} methylbutanoyl))bis(azanediyl))bis(ethane-2,1-diyl))dicarbamate (11). ${ }^{43}$ Compound 9 (0.48 g, $1.143 \mathrm{mmol}, 1$ eq.) was dissolved in acetonitrile $(150 \mathrm{~mL}), \mathrm{HOBt}(54.9 \mathrm{mg}$, $0.357 \mathrm{mmol}, 0.25$ eq.) was added followed by $\operatorname{EDC}(0.5943 \mathrm{~g}, 3.143 \mathrm{mmol}, 2.2$ eq.). Next a solution containing amine 10 (0.5714 g, $3.566 \mathrm{mmol}, 2.5$ eq. $)$ and triethylamine (0.503 mL, $3.566 \mathrm{mmol}, 2.5 \mathrm{eq}$.) in acetonitrile $(50 \mathrm{~mL})$ was added to the mixture. The solution was let to react overnight. The solvent was reduced and then dissolved in ethyl acetate $(300 \mathrm{~mL})$ and washed with $1 \mathrm{M} \mathrm{HCl}(150 \mathrm{~mL})$ followed by water $(150 \mathrm{~mL})$ then saturated sodium chloride $(150 \mathrm{~mL})$, dried with magnesium sulfate, and the solvent evaporated. The crude product was purified using flash chromatography (1:1 methylene chloride/ethyl acetate), giving a yellow powder $(0.6039 \mathrm{~g}, 68.2 \%$ yield $) . \quad\left[\mathrm{R}_{\mathrm{f}}=0.31(1: 1\right.$ methylene chloride/ethyl acetate); ${ }^{1} \mathrm{H} \mathrm{NMR}\left(400 \mathrm{MHz}, \mathrm{CDCl}_{3}\right) ; \delta(\mathrm{ppm}) 6.38(\mathrm{~s}, 2 \mathrm{H}, \mathrm{NH})$, 
$5.28(\mathrm{~s}, 2 \mathrm{H}, \mathrm{NH}), 3.23\left(\mathrm{t}, 4 \mathrm{H}, \mathrm{CH}_{2}\right), 3.18\left(\mathrm{t}, 4 \mathrm{H}, \mathrm{CH}_{2}\right), 2.70\left(\mathrm{~s}, 4 \mathrm{H}, \mathrm{CH}_{2}\right), 2.17(\mathrm{~s}, 6 \mathrm{H}$, $\mathrm{CH}_{3}$ ), 1.41 (s, $18 \mathrm{H}, \mathrm{CH}_{3}$ ), 1.39 (s, $12 \mathrm{H}, \mathrm{CH}_{3}$ ); HRMS (ESI): calcd for $\mathrm{C}_{32} \mathrm{H}_{52} \mathrm{~N}_{4} \mathrm{O}_{8}$ $[\mathrm{M}+\mathrm{H}]^{+}$621.3785; found 621.3805].

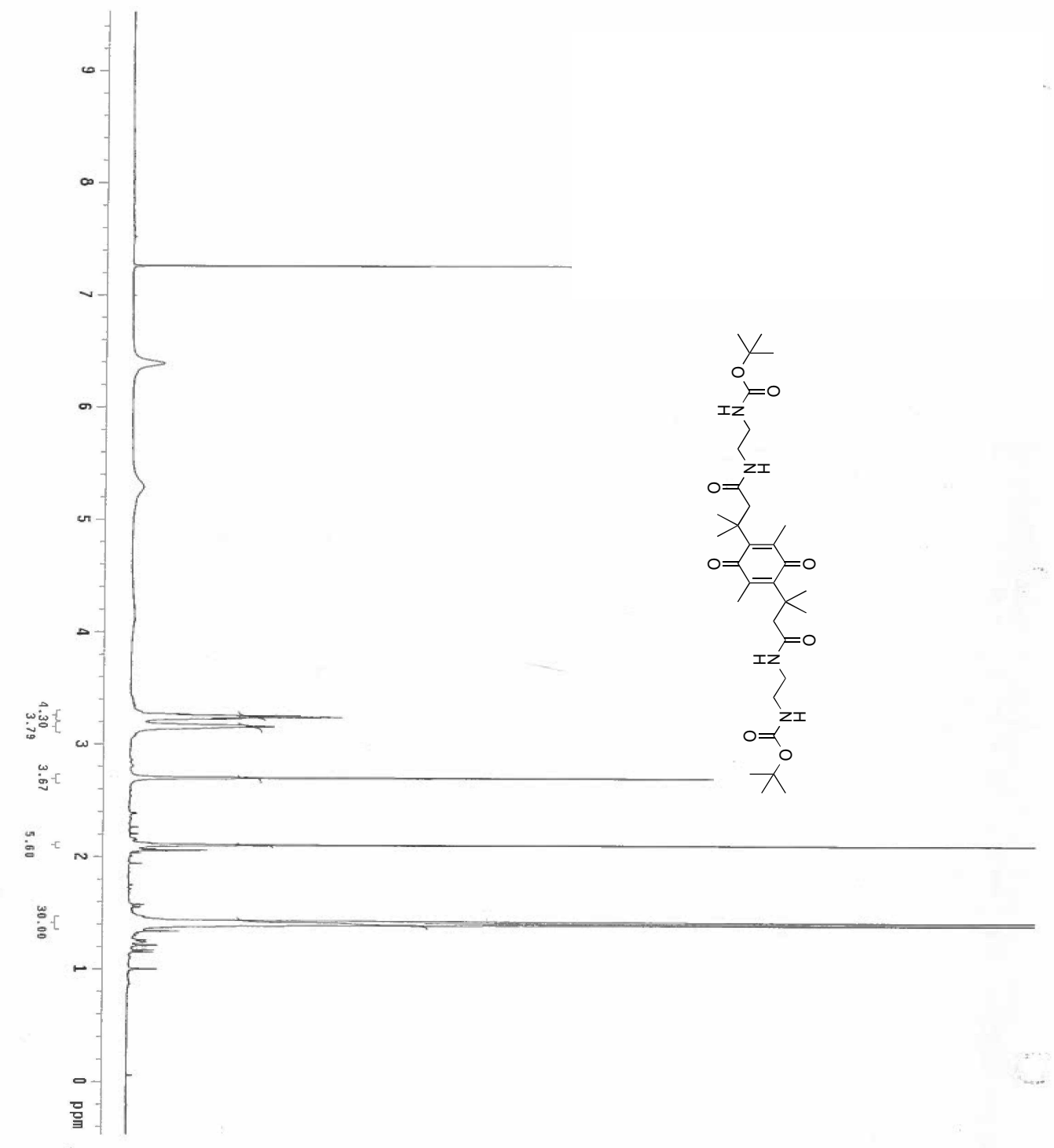

Figure 25. ${ }^{1} \mathrm{H}$ NMR spectra of di-tert-butyl (((3,3'-(2,5-dimethyl-3,6dioxocyclohexa-1,4-diene-1,4-diyl)bis(3methylbutanoyl))bis(azanediyl))bis(ethane-2,1-diyl))dicarbamate (11). 


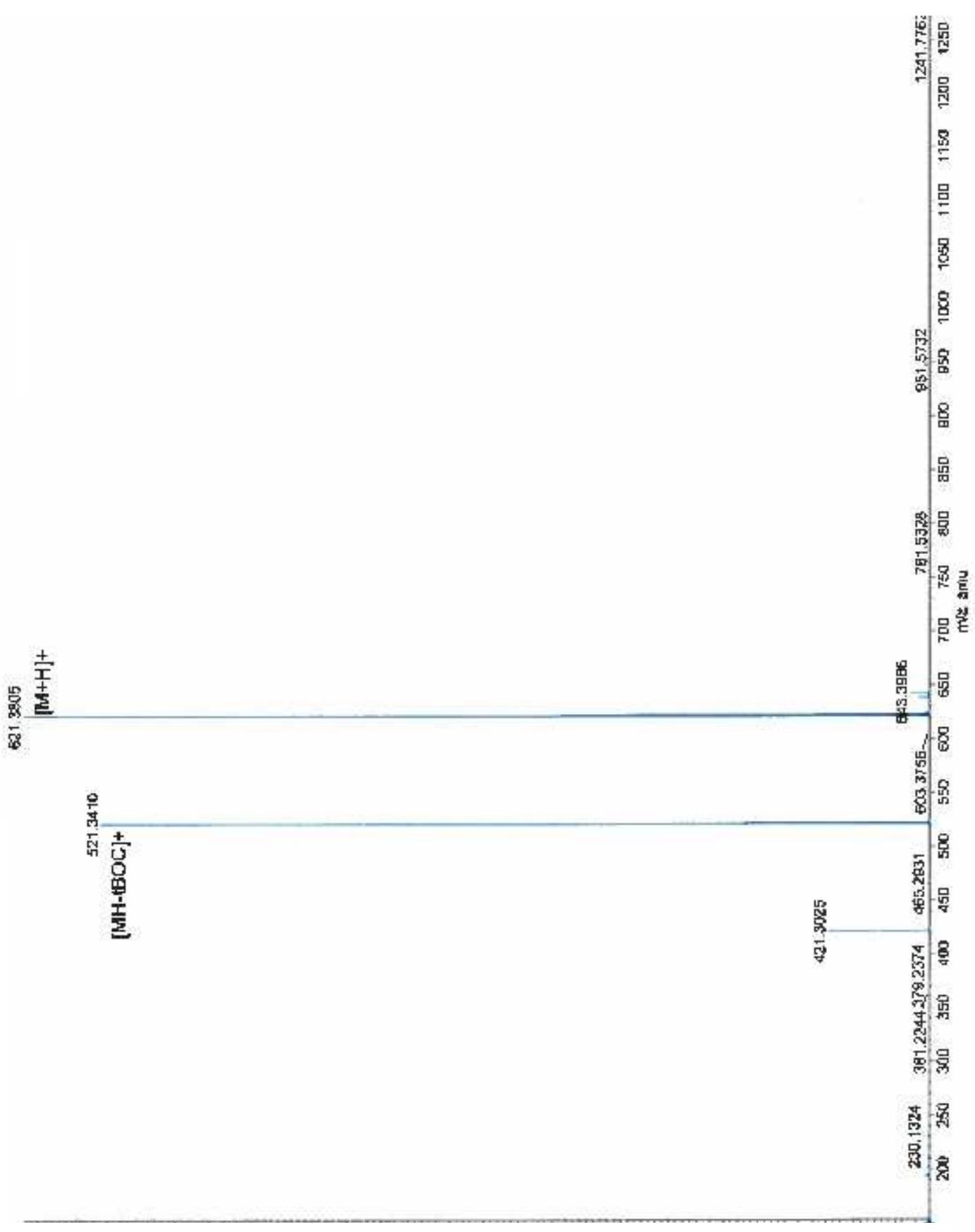

Figure 26. Mass spectra of di-tert-butyl (((3,3'-(2,5-dimethyl-3,6dioxocyclohexa-1,4-diene-1,4-diyl)bis(3methylbutanoyl))bis(azanediyl))bis(ethane-2,1-diyl))dicarbamate. 


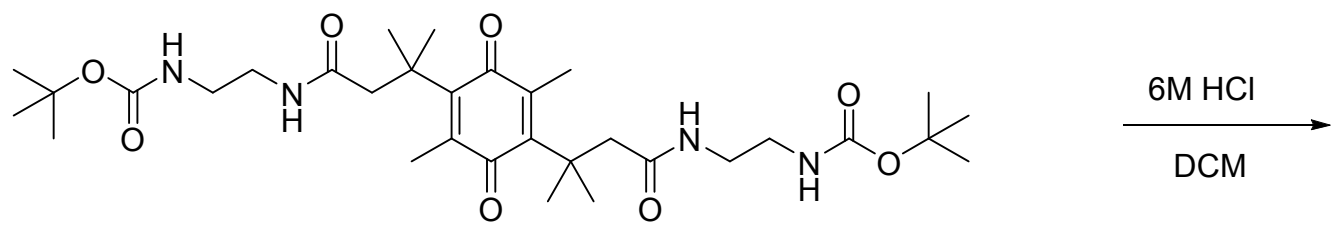

11

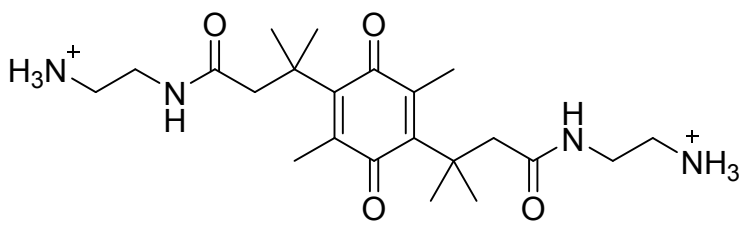

20

Figure 27. 2,2'-((3,3'-(2,5-Dimethyl-3,6-dioxocyclohexa-1,4-diene-1,4-diyl)bis(3methylbutanoyl))bis(azanediyl))bis(ethan-1-aminium) synthesis.

\section{2,2'-((3,3'-(2,5-Dimethyl-3,6-dioxocyclohexa-1,4-diene-1,4-diyl)bis(3-}

methylbutanoyl))bis(azanediyl))bis(ethan-1-aminium) (20). ${ }^{44}$ Compound $11(0.05 \mathrm{~g})$

was dissolved in methylene chloride $(10 \mathrm{~mL})$, and $6 \mathrm{M} \mathrm{HCl}(10 \mathrm{~mL})$ was added and let to react until the yellow color moved from the organic phase to the aqueous phase $(2 \mathrm{~h})$.

The aqueous layer was then separated and water was evaporated, giving a yellow solid (33.4 mg, 100\% yield). $\left[\mathrm{R}_{\mathrm{f}}=0\right.$ (ethyl acetate); ${ }^{1} \mathrm{H} \mathrm{NMR}\left(400 \mathrm{MHz}, \mathrm{D}_{2} \mathrm{O}\right): \delta(\mathrm{ppm}) 3.20(\mathrm{t}$, 4H, $\left.\left.\mathrm{CH}_{2}\right), 2.87\left(\mathrm{t}, 4 \mathrm{H}, \mathrm{CH}_{2}\right), 2.52\left(\mathrm{~s}, 4 \mathrm{H}, \mathrm{CH}_{2}\right), 1.84\left(\mathrm{~s}, 6 \mathrm{H}, \mathrm{CH}_{3}\right), 1.12\left(\mathrm{~s}, 12 \mathrm{H}, \mathrm{CH}_{3}\right)\right]$. 


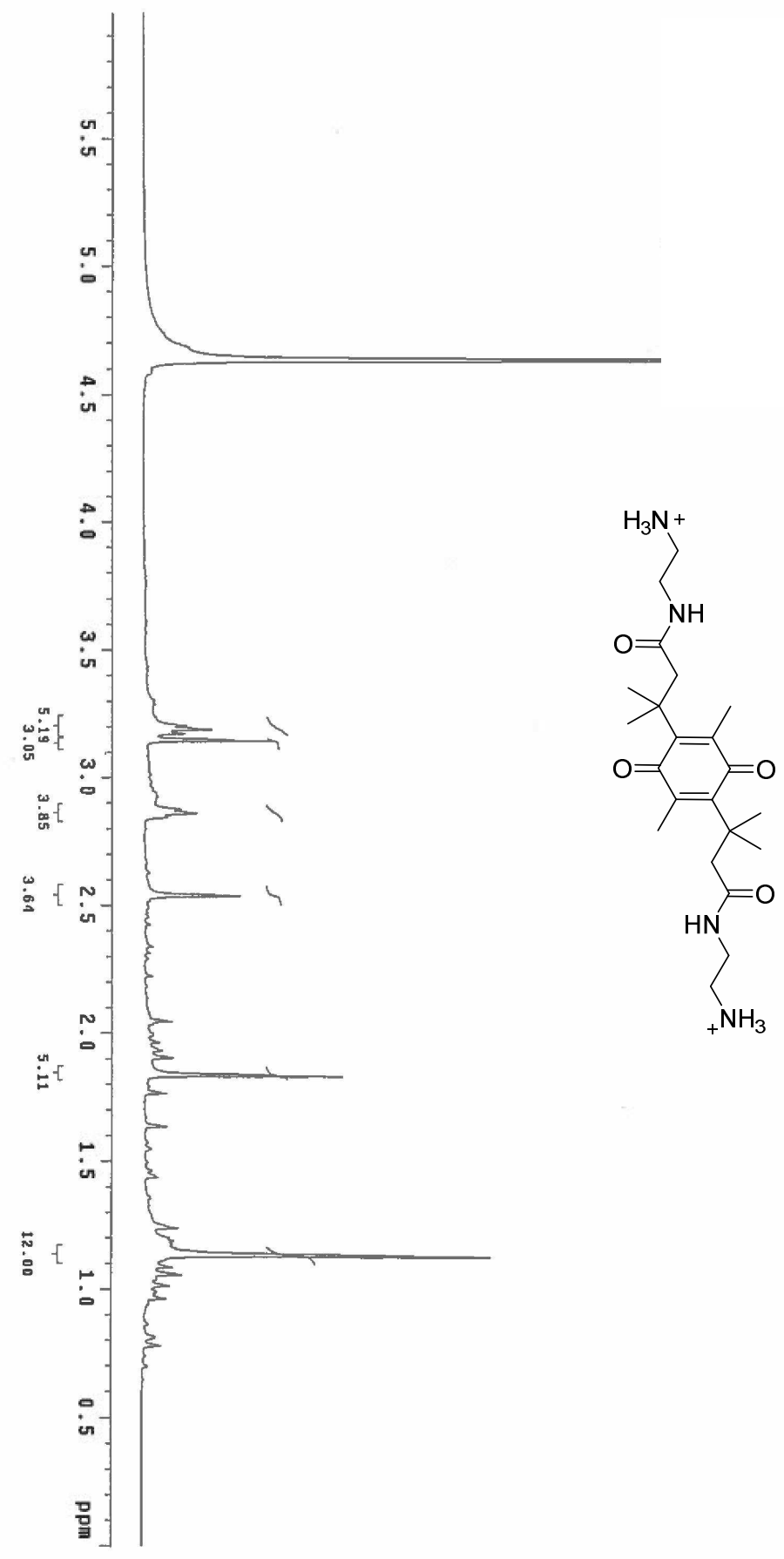

Figure 28. Crude ${ }^{1} \mathrm{H}$ NMR spectra of 2,2'-((3,3'-(2,5-dimethyl-3,6-dioxocyclohexa-1,4-diene-1,4-diyl)bis(3methylbutanoyl))bis(azanediyl))bis(ethan-1-aminium) in deuterium oxide (20). 


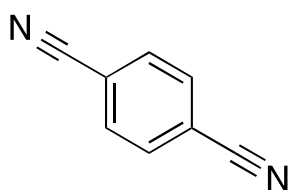

12

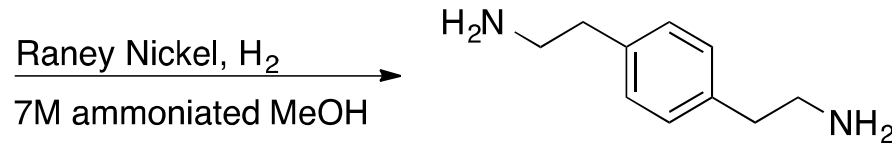

13

Figure 29. 2,2'-(1,4-Phenylene)bis(ethan-1-amine) synthesis.

\section{2,2'-(1,4-Phenylene)bis(ethan-1-amine) (13). ${ }^{45}$ Compound 12 (7.5284 g, 48.2 mmol)}

was dissolved in $7 \mathrm{M}$ ammoniated methanol $(200 \mathrm{~mL})$ in a $500 \mathrm{~mL}$ hydrogenation flask. A 50\% Raney nickel slurry solution $(\sim 4 \mathrm{~mL})$ in water was washed with methanol to remove the water and $4 \mathrm{~mL}$ of Raney nickel was measured out and added to the hydrogenation flask. The flask was then attached to a Parr hydrogenator. The air in the flask was vacuumed out then pressurized with $\mathrm{H}_{2}$ to the maximum pressure ( $\sim 55 \mathrm{psi}$ ) and then the gas was removed using a vacuum. The solution was shaken and pressurized with $\mathrm{H}_{2}$ again; this was repeated 3 more times. The reaction flask was shaken and let to react for 3 days, while continuously re-pressurizing the flask as needed. The flask was shut off from the reservoir and $\mathrm{H}_{2}$ tank to prevent gaseous ammonia from leaking into the Parr hydrogenators reservoir tank and reacting to any brass present, and also to prevent leakage of ammonia into the $\mathrm{H}_{2}$ tank. Once the $\mathrm{H}_{2}$ pressure in the reaction flask remained constant for a long period of time, the pressure was relieved and the reaction flask removed. The Raney nickel was vacuum filtered out and the solvent evaporated, yielding a thick dark brown sap-like product $\left(7.911 \mathrm{~g}, 99 \%\right.$ yield). [ $\mathrm{R}_{\mathrm{f}}=0$ (ethyl acetate); ${ }^{1} \mathrm{H}$ NMR (400 MHz, MeOD): $\delta(\mathrm{ppm}) 7.17$ (s, 4H, CH), $2.88\left(\mathrm{~m}, 4 \mathrm{H}, \mathrm{CH}_{2}\right), 2.75$ $\left.\left(\mathrm{m}, 4 \mathrm{H}, \mathrm{CH}_{2}\right)\right]$. 


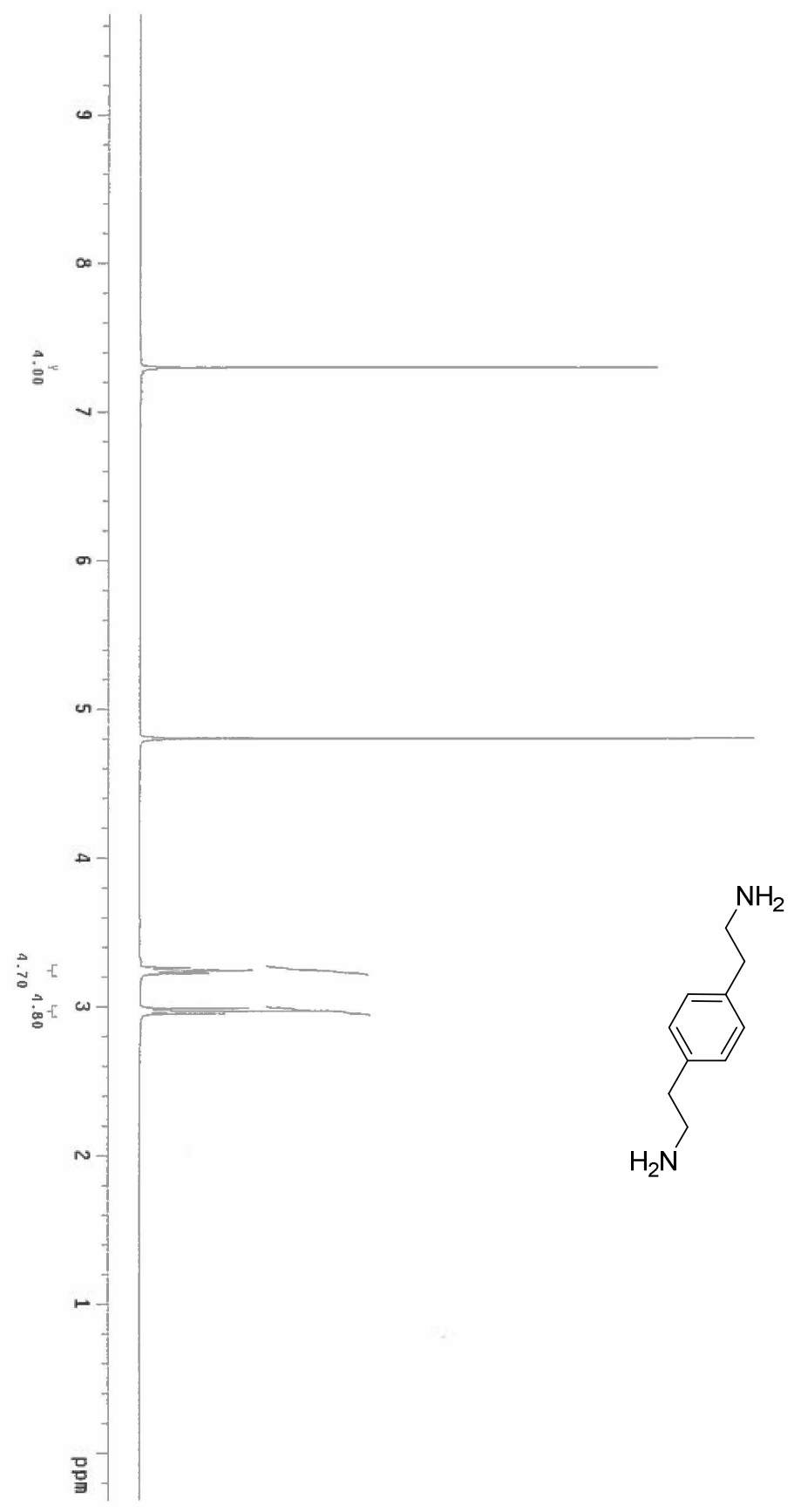

Figure 30. ${ }^{1} \mathrm{H}$ NMR spectra of 2,2'-(1,4-phenylene)bis(ethan-1-amine) in deuterated methanol (13). 


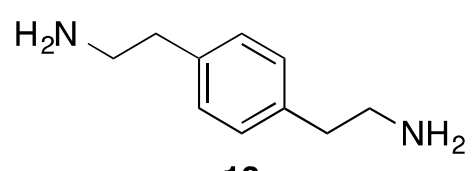

13

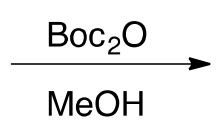

$\mathrm{MeOH}$

Figure 31. tert-Butyl (4-(2-aminoethyl)phenethyl)carbamate synthesis.

tert-Butyl (4-(2-aminoethyl)phenethyl)carbamate (14). ${ }^{37} \mathrm{Boc}_{2} \mathrm{O}(0.3356 \mathrm{~g}, 1.538$

mmol, 1 eq.) was dissolved in methanol $(25 \mathrm{~mL})$ and added dropwise to a solution of $\mathbf{1 3}$ $(1.5143 \mathrm{~g})$ in methanol $(25 \mathrm{~mL})$ at $0{ }^{\circ} \mathrm{C}$. Once all $\mathrm{Boc}_{2} \mathrm{O}$ solution was added, the ice bath was removed and the reaction let to react overnight. The solvent was evaporated and the crude product was dissolved in water $(200 \mathrm{~mL})$, the solution was vacuum filtered then extracted using methylene chloride $(3 \times 150 \mathrm{~mL})$. The organic layer was dried using magnesium sulfate and solvent was removed in vacuo, giving a white solid $(0.406 \mathrm{~g}, 99 \%$ yield). $\left[\mathrm{R}_{\mathrm{f}}=0.2\left(1: 1\right.\right.$ methylene chloride/ethyl acetate); ${ }^{1} \mathrm{H} \mathrm{NMR}\left(400 \mathrm{MHz}, \mathrm{CDCl}_{3}\right)$ : $\delta(\mathrm{ppm}) 1.43\left(\mathrm{~s}, 9 \mathrm{H}, \mathrm{CH}_{3}\right), 2.74\left(\mathrm{~m}, 4 \mathrm{H}, \mathrm{CH}_{2}\right), 2.97\left(\mathrm{~m}, 2 \mathrm{H}, \mathrm{CH}_{2}\right), 3.36\left(\mathrm{~m}, 2 \mathrm{H}, \mathrm{CH}_{2}\right)$, $\left.4.57\left(\mathrm{~s}, 2 \mathrm{H}, \mathrm{NH}_{2}\right), 7.14(\mathrm{~s}, 4 \mathrm{H}, \mathrm{CH})\right]$. 


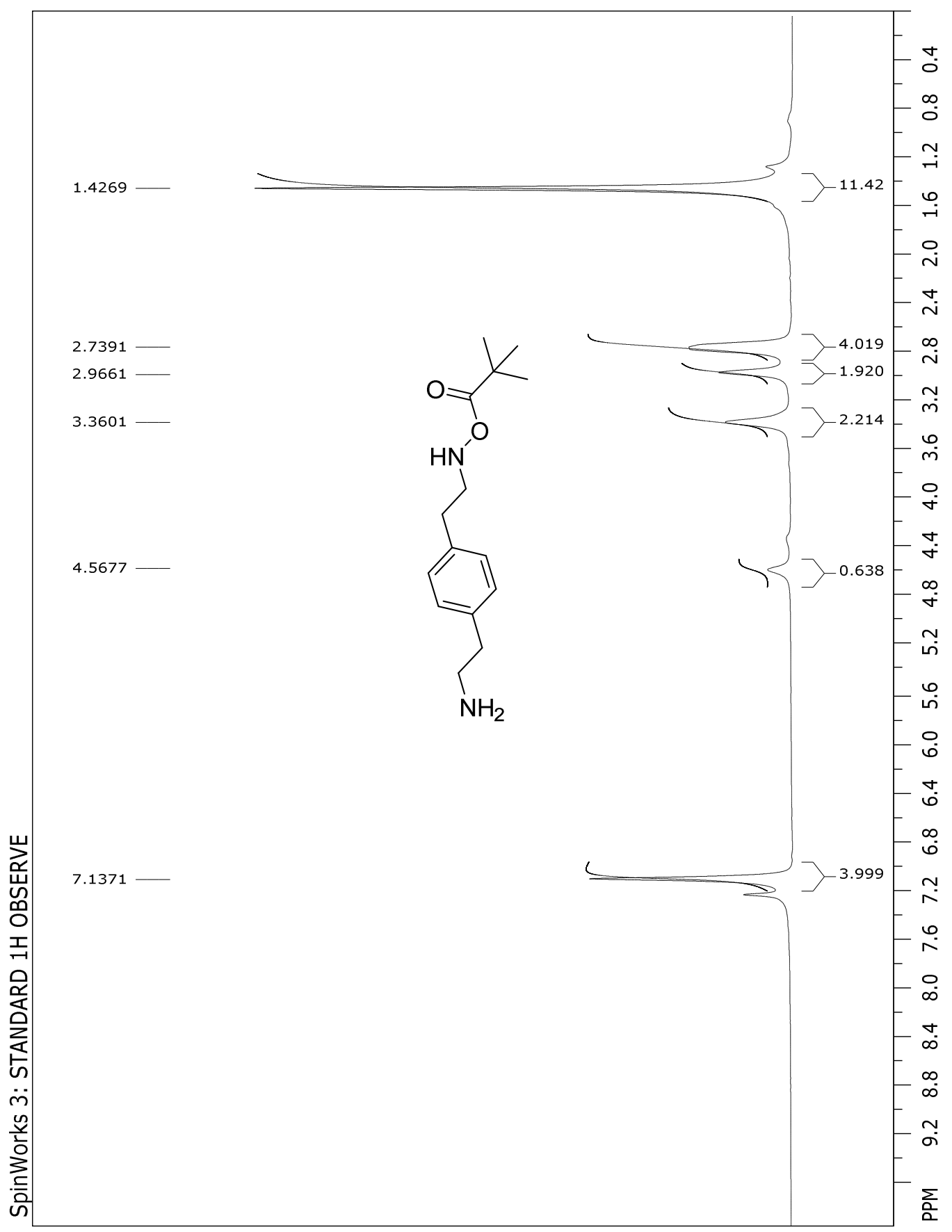

Figure 32. ${ }^{1} \mathrm{H}$ NMR spectrum of tert-butyl (4-(2aminoethyl)phenethyl)carbamate in deuterated chloroform (14). 
<smiles>CC1=C(C(C)(C)CC(=O)O)C(=O)C(C)=C(C(C)(C)CC(=O)O)C1=O</smiles>

9
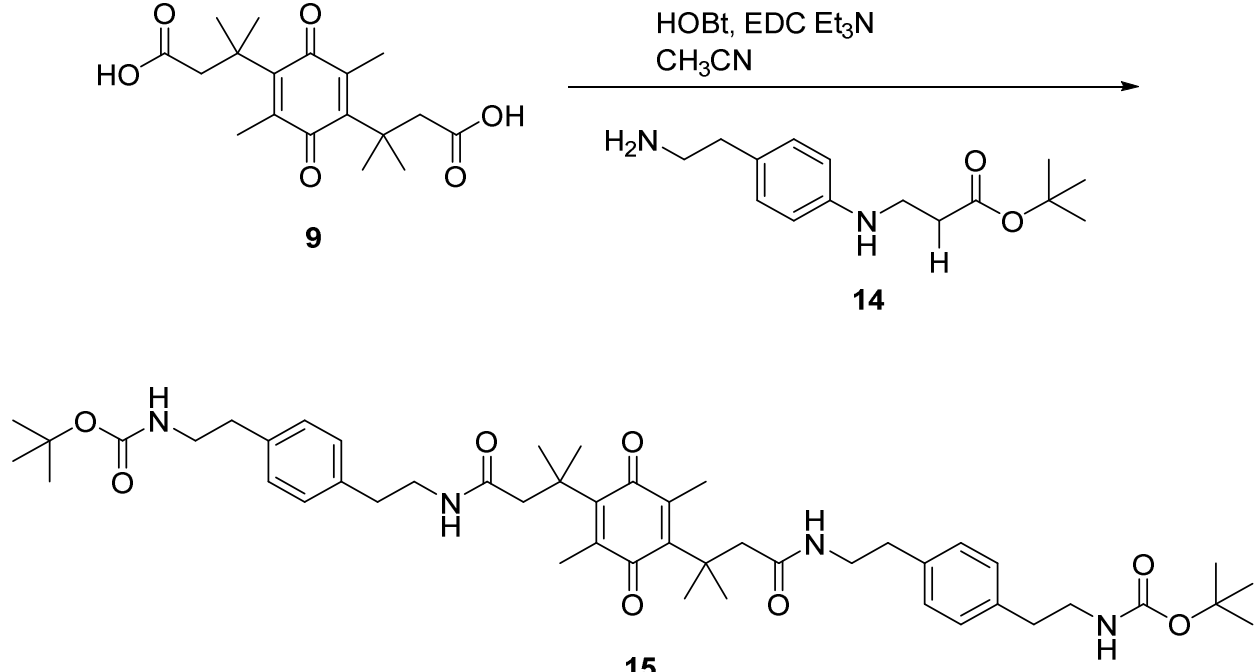

Figure 33. 3,3'-(2,5-Dimethyl-3,6-dioxocyclohexa-1,4-diene-1,4-diyl)bis(N-(4-(2aminoethyl)phenethyl)-3-methylbutanamide) synthesis.

\section{3,3'-(2,5-Dimethyl-3,6-dioxocyclohexa-1,4-diene-1,4-diyl)bis(N-(4-(2-}

aminoethyl)phenethyl)-3-methylbutanamide) (15). ${ }^{43}$ Compound $9(0.2636 \mathrm{~g}, 0.7845$

mmol, 1 eq.) was dissolved by stirring in acetonitrile $(150 \mathrm{~mL})$, followed by HOBt (30.0 $\mathrm{mg}, 0.1961 \mathrm{mmol}, 0.25$ eq.), and EDC (0.3309 g, $1.726 \mathrm{mmol}, 2.2$ eq.). Next, a solution containing amine $10(0.5181 \mathrm{~g}, 1.961 \mathrm{mmol}, 2.5 \mathrm{eq}$.$) and triethylamine (0.2736 \mathrm{~mL}$, $1.961 \mathrm{mmol}, 2.5$ eq.) in acetonitrile $(50 \mathrm{~mL})$ was added to the stirring solution containing compound 9. This solution was let to react overnight. The solvent was reduced and then dissolved in ethyl acetate $(300 \mathrm{~mL})$ and washed with $1 \mathrm{M} \mathrm{HCl}(150 \mathrm{~mL})$, followed by water $(150 \mathrm{~mL})$, then saturated sodium chloride $(150 \mathrm{~mL})$, dried with magnesium sulfate, and the solvent evaporated. The crude product was purified using flash chromatography (1:1 methylene chloride/ethyl acetate) giving a yellow oil $\left(0.261 \mathrm{~g}, 40.2 \%\right.$ yield). [ $\mathrm{R}_{\mathrm{f}}=$ 0.4 (1:1 methylene chloride/ethyl acetate); ${ }^{1} \mathrm{H}$ NMR (400 MHz, $\left.\mathrm{CDCl}_{3}\right): \delta(\mathrm{ppm}) 1.39$ (s, 
$\left.12 \mathrm{H}, \mathrm{CH}_{3}\right), 1.42$ (s, $18 \mathrm{H}, \mathrm{CH}_{3}$ ), 2.11 (s, 6H, $\left.\mathrm{CH}_{3}\right), 2.95-2.55\left(\mathrm{~m}, 12 \mathrm{H}, \mathrm{CH}_{2}\right), 3.45-3.20$ (m, 8H, $\mathrm{CH}_{2}$ ), 7.07 (s, 8H, CH); HRMS (ESI): calcd for $\mathrm{C}_{48} \mathrm{H}_{68} \mathrm{~N}_{4} \mathrm{O}_{8}[\mathrm{M}+\mathrm{H}]^{+}$829.5037; found 829.5416].

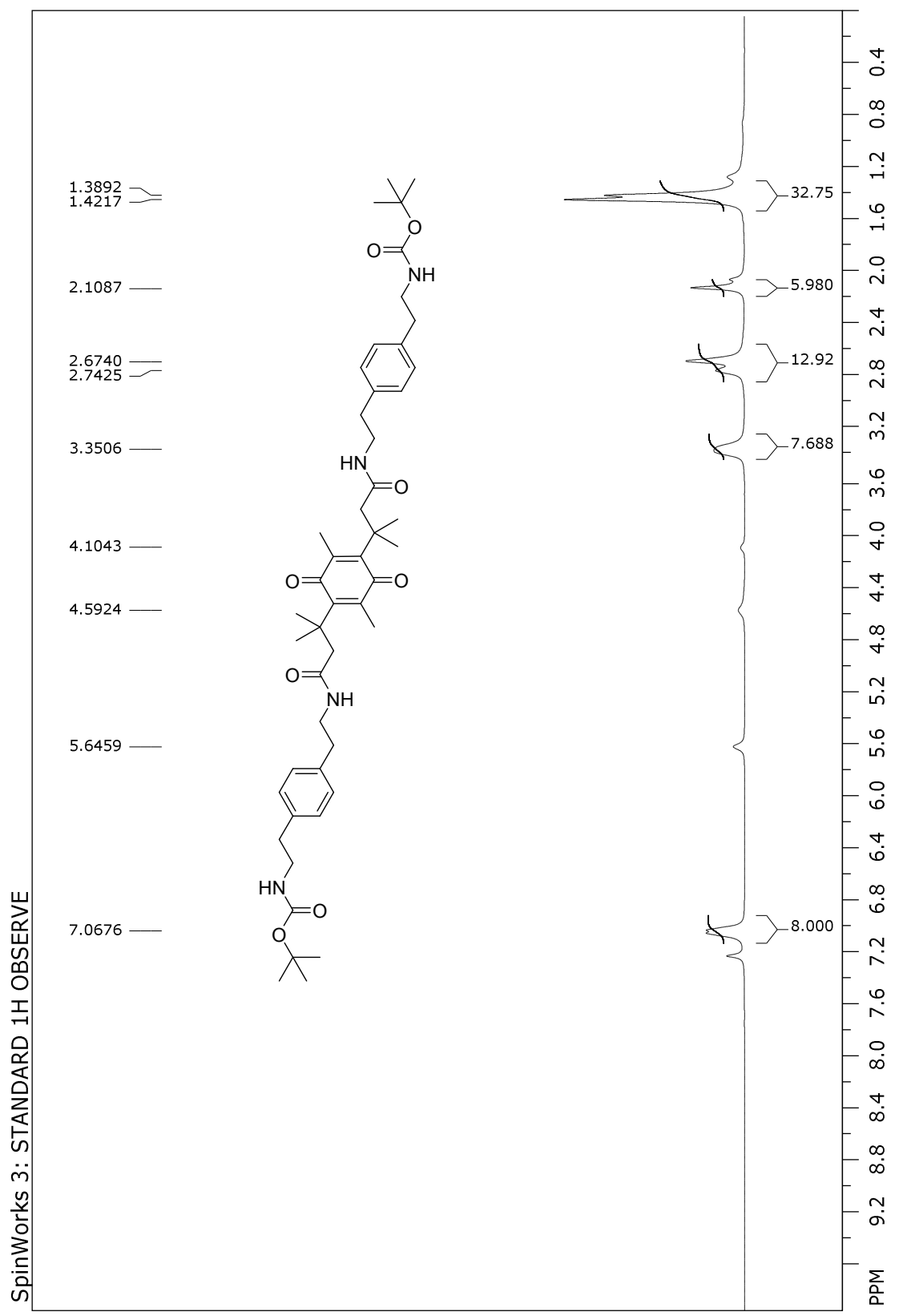

Figure 34. ' ${ }^{1} \mathrm{H}$ NMR spectrum of 3,3'-(2,5-dimethyl-3,6-dioxocyclohexa-1,4diene-1,4-diyl)bis(N-(4-(2-aminoethyl)phenethyl)-3-methylbutanamide) in deuterated chloroform (15). 


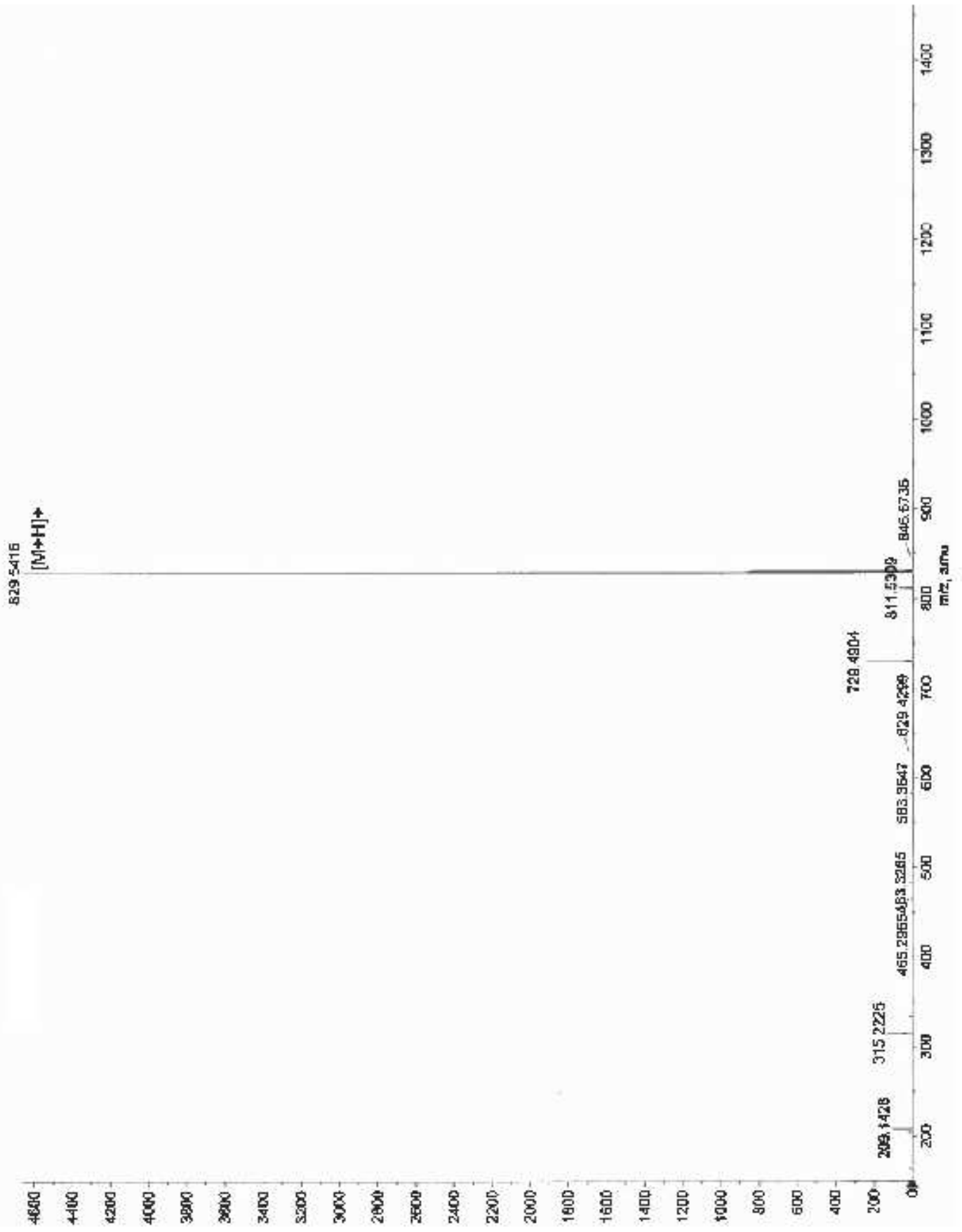

Figure 35. Mass spectra of 3,3'-(2,5-dimethyl-3,6-dioxocyclohexa-1,4-diene1,4diyl)bis(N-(4-(2-aminoethyl)phenethyl)-3-methylbutanamide). 


\section{REFERENCES}

1. Feizi, T.; Chai, W. Nat. Rev. Mol. Cell Biol. 2004, 5, 582-588.

2. Painter, P.C.; Coleman, M.M. Fundamentals of Polymer Science: An Introductory Text 1997, Lancaster, Pa.: Technomic Pub. Co. 1.

3. Odian, G.G. Principle of Polymerization, $4^{\text {th }}$ ed.; John Wiley \& Sons: New Jersey, 2004.

4. Karak, N. Fundamentals of Polymers, $1^{\text {st }}$ ed.; PHI Learning Private Limited: New Delhi, 2009.

5. Whelan, T. Polymer Technology Dictionary, $1^{\text {st }}$ ed.; Chapman \& Hall: London, 1994.

6. Ebewele, R.O. Polymer Science and Technology, 1st ed. ; CRC Press: Florida, 2000.

7. Cho, S.; Sea, J.H.; Park, S.H.; Beaupre, S.; Leclare, M.; Heager, A.J. Advanced Materials 2010, 22:11, 1253-1257.

8. Peacock, A.J.; Calhoun, A.R. Polymer Chemistry: Properties and Applications, $1^{\text {st }}$ ed.; Hanser Gardner Publications: Ohil, 2006.

9. Furukawa, Yasu. Inventing Polymer Science: Staudinger, Carothers, and the Emergency of Macromolecular Science. University of Pennsylvania Press: Philadelphia, 1998.

10. Hoare, T.R.; Kohane, D.S. Polymer 2008, 49, 1993-2007.

11. Lakovlev, V.; Guelcher, S.; Bendavid, R. Degradation of polypropylene in vivo: A microscopic analysis of meshes explanted from patients. J. Biomed. Mater. Res. Part B: Appl. Biomater. 2015.

12. Munro, C.J.; Laughlin, L.S.; VonSchalscha, T.; Baldwin, D. M.; Lasley, B. L. Contraception 1996, 54, 43-53.

13. Vogelson, C.T. Modern Drug Discovery 2001, 4, 49-52.

14. Wolinsky, J.B.; Grinstaff, M.W. Advanced Drug Delivery Reviews 2008, 60, 10371055.

15. Dash, A.K.; Cudworth, G. Journal of Pharmacological and Toxicological Methods 1998, 40, 1-12. 
16. Mainardes, R.M.; Silva, L.P. Current Drug Targets 2004, 5, 449-455.

17. Chang, C.; Duan, B.; Dai, J.; Zhang, L. J. Eur. Polym. J. 2010, 46, 1515-1518.

18. Li, J.; Kuang, Y.; Gazo, Y.; Du, X.; Shi, J.; Xu, B. J. Am. Chem. Soc. 2013, 135, 542545.

19. Yan, B.; Boyer, J.; Habsult, D.; Branda, N.; Zhao, Y. J. Am. Chem. Soc. 2012, 134, 16558-16561.

20. Tarkul, Vivian Jan, "Design and synthesis of electrochemically degradable hydrogels" (2013). Master's Thesis. Paper 4316.

21. Meijer, E. W. Science, 1994, 266, 1226.

22. Watkins, D.M.; Sweet, Y.S.; Kimash, J.W.; Turro, N.J.; Tomalia, D.A. Langmuir, 1997, 13, 3136-3141.

23. Gopferich, A. Biomaterials 1996, 17, 103-114.

24. Svirskis, D.; Travas-Sejdic, J.; Rodgers, A.; Garg, S. J. Controlled Release 2010, 146, 6-15.

25. Runge, M.; Dadstein, M.; Baltrusaitis, J.; Ruesink, T.; Lu, L.; Windebask, A.; Yascemski, M. Biomacromolecule 2010, 11, 2845-2853.

26. Pernaut, J.; Reynolds, J.R. J. Phys. Chem. B. 2000, 104, 4080-4090.

27. Entezami, A.A.; Massoumi, B. J. Iranian Polymer 2006, 1, 13-30.

28. Beesley, R.M.; Ingold, C.K.; Thorpe, J.F. J. Chem. Soc., Trans. 1915, 107, $1080-$ 1106.

29. Borchardt, R.T.; Cohen, L.A. J. Am. Chem. Soc. 1973, 95, 8308-8313.

30. Karle, J.M.; Karle, I.L. J. Am. Chem. Soc. 1972, 94, 9182-9189.

31. Tarkul, V.; Ramphal, J.; d'Alarcao, M. San Jose State University, San Jose, CA. Unpublished work, 2010.

32. Carpino, L.A.; Triolo, S. A.; Berglund, R. A. J. Org. Chem. 1988, 89, 3303-3310.

33. Carpino, L.A.; Triolo, S. A.; Berglund, R. A. J. Org. Chem. 1989, 54, 3303-3310.

34. Grigoriu, S.; d'Alarcao, M. Tufts university, Boston, MA. Unpublished work, 2007. 
35. Meenakshisundaram, Anuradha, Synthesis and Studies of Polymers Crosslinked with Electrochemically Degradable Crosslinking Reagents (2011). Master's Thesis. Paper 3945.

36. Pickup, P.G.; Kutner, W.; Leidner, C.R.; Murray, R.W. J. Am. Chem. Soc. 1984, 106, 1991-1998.

37. Cao, W.; Zhu, L. Macromolecule 2011, 44, 1500-1512.

38. Konig, W.; Geiger, R. Chemiche Berichte 1970, 103, 788-789.

39. Shendage, D.M.; Froehlich, R.; Haufe, G. Org. Lett. 2004, 6, 3675-3678.

40. Liotta, D.; Arbiser, J. J. Org. Chem. 1983, 48, 2932-2933.

41. Patel, A.; Liebner, F.; Netscher, T.; Mereiter, K.; Rosenau, T. J. Org. Chem. 2007, $72,6504-6512$.

42. Milstein, S.; Cohen, L. A. J. Am. Chem. Soc. 1970, 92, 4377-4382.

43. Xu, L.; Cheng, J.; Trudell, M.L. J. Org. Chem. 2003, 68, 5388-5391.

44. Albrecht, S.; Defoin, A.; Tarnus, C. Synthesis 2006, 10, 1635-1638.

45. Denton, T.T.; Joyce, A.S.; Kiely, D.E. J. Org. Chem. 2007, 72, 4997-5000. 


\section{REFERENCES}

1. Feizi, T.; Chai, W. Nat. Rev. Mol. Cell Biol. 2004, 5, 582-588.

2. Painter, P.C.; Coleman, M.M. Fundamentals of Polymer Science: An Introductory Text 1997, Lancaster, Pa.: Technomic Pub. Co. 1.

3. Odian, G.G. Principle of Polymerization, $4^{\text {th }}$ ed.; John Wiley \& Sons: New Jersey, 2004.

4. Karak, N. Fundamentals of Polymers, $1^{\text {st }}$ ed.; PHI Learning Private Limited: New Delhi, 2009.

5. Whelan, T. Polymer Technology Dictionary, $1^{\text {st }}$ ed.; Chapman \& Hall: London, 1994.

6. Ebewele, R.O. Polymer Science and Technology, $1^{\text {st }}$ ed. ; CRC Press: Florida, 2000.

7. Cho, S.; Sea, J.H.; Park, S.H.; Beaupre, S.; Leclare, M.; Heager, A.J. Advanced Materials 2010, 22:11, 1253-1257.

8. Peacock, A.J.; Calhoun, A.R. Polymer Chemistry: Properties and Applications, $1^{\text {st }}$ ed.; Hanser Gardner Publications: Ohil, 2006.

9. Furukawa, Yasu. Inventing Polymer Science: Staudinger, Carothers, and the Emergency of Macromolecular Science. University of Pennsylvania Press: Philadelphia, 1998.

10. Hoare, T.R.; Kohane, D.S. Polymer 2008, 49, 1993-2007.

11. Lakovlev, V.; Guelcher, S.; Bendavid, R. Degradation of polypropylene in vivo: A microscopic analysis of meshes explanted from patients. J. Biomed. Mater. Res. Part B: Appl. Biomater. 2015.

12. Munro, C.J.; Laughlin, L.S.; VonSchalscha, T.; Baldwin, D. M.; Lasley, B. L. Contraception 1996, 54, 43-53.

13. Vogelson, C.T. Modern Drug Discovery 2001, 4, 49-52.

14. Wolinsky, J.B.; Grinstaff, M.W. Advanced Drug Delivery Reviews 2008, 60, 10371055.

15. Dash, A.K.; Cudworth, G. Journal of Pharmacological and Toxicological Methods 1998, 40, 1-12. 
16. Mainardes, R.M.; Silva, L.P. Current Drug Targets 2004, 5, 449-455.

17. Chang, C.; Duan, B.; Dai, J.; Zhang, L. J. Eur. Polym. J. 2010, 46, 1515-1518.

18. Li, J.; Kuang, Y.; Gazo, Y.; Du, X.; Shi, J.; Xu, B. J. Am. Chem. Soc. 2013, 135, 542545.

19. Yan, B.; Boyer, J.; Habsult, D.; Branda, N.; Zhao, Y. J. Am. Chem. Soc. 2012, 134, 16558-16561.

20. Tarkul, Vivian Jan, "Design and synthesis of electrochemically degradable hydrogels" (2013). Master's Thesis. Paper 4316.

21. Meijer, E. W. Science, 1994, 266, 1226.

22. Watkins, D.M.; Sweet, Y.S.; Kimash, J.W.; Turro, N.J.; Tomalia, D.A. Langmuir, 1997, 13, 3136-3141.

23. Gopferich, A. Biomaterials 1996, 17, 103-114.

24. Svirskis, D.; Travas-Sejdic, J.; Rodgers, A.; Garg, S. J. Controlled Release 2010, 146, 6-15.

25. Runge, M.; Dadstein, M.; Baltrusaitis, J.; Ruesink, T.; Lu, L.; Windebask, A.; Yascemski, M. Biomacromolecule 2010, 11, 2845-2853.

26. Pernaut, J.; Reynolds, J.R. J. Phys. Chem. B. 2000, 104, 4080-4090.

27. Entezami, A.A.; Massoumi, B. J. Iranian Polymer2006, 1, 13-30.

28. Beesley, R.M.; Ingold, C.K.; Thorpe, J.F. J. Chem. Soc., Trans. 1915, 107, 10801106.

29. Borchardt, R.T.; Cohen, L.A. J. Am. Chem. Soc. 1973, 95, 8308-8313.

30. Karle, J.M.; Karle, I.L. J. Am. Chem. Soc. 1972, 94, 9182-9189.

31. Tarkul, V.; Ramphal, J.; d'Alarcao, M. San Jose State University, San Jose, CA. Unpublished work, 2010.

32. Carpino, L.A.; Triolo, S. A.; Berglund, R. A. J. Org. Chem. 1988, 89, 3303-3310.

33. Carpino, L.A.; Triolo, S. A.; Berglund, R. A. J. Org. Chem. 1989, 54, 3303-3310. 
34. Grigoriu, S.; d'Alarcao, M. Tufts university, Boston, MA. Unpublished work, 2007.

35. Meenakshisundaram, Anuradha, Synthesis and Studies of Polymers Crosslinked with Electrochemically Degradable Crosslinking Reagents (2011). Master's Thesis. Paper 3945.

36. Pickup, P.G.; Kutner, W.; Leidner, C.R.; Murray, R.W. J. Am. Chem. Soc. 1984, 106, 1991-1998.

37. Cao, W.; Zhu, L. Macromolecule 2011, 44, 1500-1512.

38. Konig, W.; Geiger, R. Chemiche Berichte 1970, 103, 788-789.

39. Shendage, D.M.; Froehlich, R.; Haufe, G. Org. Lett. 2004, 6, 3675-3678.

40. Liotta, D.; Arbiser, J. J. Org. Chem. 1983, 48, 2932-2933.

41. Patel, A.; Liebner, F.; Netscher, T.; Mereiter, K.; Rosenau, T. J. Org. Chem. 2007, $72,6504-6512$.

42. Milstein, S.; Cohen, L. A. J. Am. Chem. Soc. 1970, 92, 4377-4382.

43. Xu, L.; Cheng, J.; Trudell, M.L. J. Org. Chem. 2003, 68, 5388-5391.

44. Albrecht, S.; Defoin, A.; Tarnus, C. Synthesis 2006, 10, 1635-1638.

45. Denton, T.T.; Joyce, A.S.; Kiely, D.E. J. Org. Chem. 2007, 72, 4997-5000. 